\title{
Technology-Enabled Remote Monitoring and Self-Management Vision for Patient Empowerment Following Cardiac and Vascular Surgery: User Testing and Randomized Controlled Trial Protocol
}

Michael McGillion ${ }^{1,2}$, RN, PhD; Jennifer Yost ${ }^{1}, \mathrm{RN}, \mathrm{PhD}$; Andrew Turner ${ }^{3}, \mathrm{PhD}, \mathrm{HCPC}, \mathrm{RHP}, \mathrm{MBPsS}$; Duane Bender $^{4}$, PEng; Ted Scott ${ }^{4}$, MAppSc, PhD; Sandra Carroll ${ }^{1,2}$, RN, PhD; Paul Ritvo ${ }^{5}$ PhD, CPsych; Elizabeth Peter ${ }^{6}$, RN, PhD; Andre Lamy ${ }^{1,2}$, MD, MHSc, FRCSC; Gill Furze ${ }^{3}, \mathrm{RN}, \mathrm{PhD}$; Kirsten Krull ${ }^{7}$, RN, BAAN, MHSc, CHE; Valerie Dunlop ${ }^{2}$, BSc; Amber Good ${ }^{2}$, MSc, CCRP; Nazari Dvirnik ${ }^{1,2}$, BHSc, MD, MS; Debbie Bedini ${ }^{7}$, BScN, RN, MHS; Frank Naus ${ }^{7}$, MSc, MBA, DBA(c); Shirley Pettit ${ }^{2}$, RN; Shaunattonie Henry ${ }^{1}$, RN, MN, MAEd, CIC; Christine Probst $^{7}$, BScN, RN, MScEd, MBA; Joseph Mills ${ }^{8}$, BChir, MD, MA, MB, FRCP; Elaine Gossage ${ }^{8}$, RN; Irene Travale ${ }^{7}$, MScN, NP; Janine Duquette ${ }^{7}$, BScN, MN, ACNP; Christy Taberner ${ }^{4}$, OT Reg; Sanjeev Bhavnani ${ }^{9}$, MD; James S $\mathrm{Khan}^{2}$, MD, MSc; David Cowan ${ }^{1}$, MD, FRCP(C); Eric Romeril ${ }^{7}$, BSc, BSc Pharm, RPh, ACPR; John Lee ${ }^{1,2}$, MD; Tracey Colella ${ }^{10}$, RN, PhD; Manon Choinière ${ }^{11}$, PhD; Jason Busse ${ }^{1}$, BSc, MSc, DC, PhD; Joel Katz ${ }^{5}$, PhD, CPsych; J Charles Victor $^{6}$, MSc, PStat; Jeffrey Hoch ${ }^{12}$, MA, PhD; Wanrudee Isaranuwatchai ${ }^{6,12}$, BSc, PhD; Sharon Kaasalainen ${ }^{1}$, BScN, RN, MSc, PhD; Salima Ladak ${ }^{10}, \mathrm{RN}, \mathrm{MN}, \mathrm{NP}, \mathrm{PhD}$; Sheila O'Keefe-McCarthy ${ }^{13}, \mathrm{RN}, \mathrm{PhD}$; Monica Parry ${ }^{6}$, NP, PhD; Daniel I Sessler ${ }^{14}$, MD; Michael Stacey ${ }^{1,7}$, DS, FRACS; Bonnie Stevens ${ }^{6}, \mathrm{RN}, \mathrm{PhD}$; Robyn Stremler ${ }^{6}, \mathrm{RN}$, $\mathrm{PhD}$; Lehana Thabane ${ }^{1}$, BSc, MSc, PhD; Judy Watt-Watson ${ }^{6}$, RN, PhD; Richard Whitlock ${ }^{2}$, MD, PhD, FRCSC; Joy C MacDermid ${ }^{1}$, BSc, BScPT, MSc, PhD; Marit Leegaard ${ }^{15}$, RN, PhD; Robert McKelvie ${ }^{7}$, BSc, MD, MSc, PhD, FRCP(C); Michael Hillmer ${ }^{6,16}$, MSc, PhD; Lynn Cooper ${ }^{17}$, BES; Gavin Arthur ${ }^{18}$, MBA, PhD; Krista Sider ${ }^{16}, \mathrm{PhD}$; Susan Oliver ${ }^{19}$, BSc, CAE; Karen Boyajian ${ }^{7}$, RN, BScN, BA, MScN; Mark Farrow ${ }^{7}$, BComm, MBA; Chris Lawton ${ }^{7}$, BMET, CCNA; Darryl Gamble ${ }^{2}$, BMath; Jake Walsh ${ }^{7}$, NE Dip; Mark Field ${ }^{8}$, DPhil, FRCS (CTh); Sandra LeFort ${ }^{20}$, $\mathrm{RN}, \mathrm{PhD}$; Wendy Clyne ${ }^{3}, \mathrm{PhD}$; Maria Ricupero ${ }^{10}$, MHSc, CDE, RD; Laurie Poole ${ }^{21}$, BScN, MHSA; Karsten Russell-Wood $^{22}$, BA, MBA, MPH; Michael Weber ${ }^{22}$, BSc; Jolene McNeill2 ${ }^{22}$ BScN, MHSc, CHE; Robyn Alpert ${ }^{22}$, RN, BScN, MN; Sarah Sharpe ${ }^{23}$, BSc (Hons), MSc; Sue Bhella ${ }^{23}$, BHSc, MPH; David Mohajer ${ }^{24}$, BComm; Sem Ponnambalam $^{24}$, BA (Hons), MA; Naeem Lakhani ${ }^{25}$; Rabia Khan ${ }^{25}$, MBA, PhD; Peter Liu ${ }^{26}$, MD, FRCPC; PJ Devereaux $^{1,2}, \mathrm{MD}, \mathrm{PhD}, \mathrm{FRCPC}$

\footnotetext{
${ }^{1}$ McMaster University, Hamilton, ON, Canada

${ }^{2}$ Population Health Research Institute, Hamilton, ON, Canada

${ }^{3}$ Coventry University, Coventry, United Kingdom

${ }^{4}$ Mohawk College, Hamilton, ON, Canada

${ }^{5}$ York University, Toronto, ON, Canada

${ }^{6}$ University of Toronto, Toronto, ON, Canada

${ }^{7}$ Hamilton Health Sciences, Hamilton, ON, Canada

${ }^{8}$ Liverpool Heart and Chest Hospital, Liverpool, United Kingdom

${ }^{9}$ Scripps Clinic and Research Institute, La Jolla, CA, United States

${ }^{10}$ University Health Network, Toronto, ON, Canada

${ }^{11}$ University of Montreal, Montreal, QC, Canada

${ }^{12}$ St. Michael's Hospital, Toronto, ON, Canada

${ }^{13}$ Brock University, St. Catharines, ON, Canada

${ }^{14}$ Cleveland Clinic, Cleveland, $\mathrm{OH}$, United States

${ }^{15}$ Oslo and Akershus University College of Applied Sciences, Oslo, Norway

${ }^{16}$ Ministry of Health and Long-Term Care, Toronto, ON, Canada

${ }^{17}$ Canadian Pain Coalition, Toronto, ON, Canada
} 
${ }^{18}$ Heart and Stroke Foundation, Ottawa, ON, Canada

${ }^{19}$ Canadian Cardiovascular Society, Ottawa, ON, Canada

${ }^{20}$ Memorial University Of Newfoundland, St. Johns, NL, Canada

${ }^{21}$ Ontario Telemedicine Network, Toronto, ON, Canada

${ }^{22}$ Philips, Toronto, ON, Canada

${ }^{23}$ QoC Health, Toronto, ON, Canada

${ }^{24}$ XAHIVE, Toronto, ON, Canada

${ }^{25}$ mPath, Toronto, ON, Canada

${ }^{26}$ University of Ottawa Heart Institute, Ottawa, ON, Canada

\section{Corresponding Author:}

Michael McGillion, RN, PhD

McMaster University

1280 Main Street West HSC 2J40E

Hamilton, ON, L8S4K1

Canada

Phone: 19055259140 ext 20275

Fax: 19055700667

Email: $\underline{\text { mmcgill@mcmaster.ca }}$

\section{Abstract}

Background: Tens of thousands of cardiac and vascular surgeries (CaVS) are performed on seniors in Canada and the United Kingdom each year to improve survival, relieve disease symptoms, and improve health-related quality of life (HRQL). However, chronic postsurgical pain (CPSP), undetected or delayed detection of hemodynamic compromise, complications, and related poor functional status are major problems for substantial numbers of patients during the recovery process. To tackle this problem, we aim to refine and test the effectiveness of an eHealth-enabled service delivery intervention, TecHnology-Enabled remote monitoring and Self-MAnagemenT-VIsion for patient EmpoWerment following Cardiac and VasculaR surgery (THE SMArTVIEW, CoVeRed), which combines remote monitoring, education, and self-management training to optimize recovery outcomes and experience of seniors undergoing CaVS in Canada and the United Kingdom.

Objective: Our objectives are to (1) refine SMArTVIEW via high-fidelity user testing and (2) examine the effectiveness of SMArTVIEW via a randomized controlled trial (RCT).

Methods: CaVS patients and clinicians will engage in two cycles of focus groups and usability testing at each site; feedback will be elicited about expectations and experience of SMArTVIEW, in context. The data will be used to refine the SMArTVIEW eHealth delivery program. Upon transfer to the surgical ward (ie, post-intensive care unit [ICU]), $256 \mathrm{CaVS}$ patients will be reassessed postoperatively and randomly allocated via an interactive Web randomization system to the intervention group or usual care. The SMArTVIEW intervention will run from surgical ward day 2 until 8 weeks following surgery. Outcome assessments will occur on postoperative day 30; at week 8; and at 3, 6, 9, and 12 months. The primary outcome is worst postop pain intensity upon movement in the previous 24 hours (Brief Pain Inventory-Short Form), averaged across the previous 14 days. Secondary outcomes include a composite of postoperative complications related to hemodynamic compromise-death, myocardial infarction, and nonfatal stroke - all-cause mortality and surgical site infections, functional status (Medical Outcomes Study Short Form-12), depressive symptoms (Geriatric Depression Scale), health service utilization-related costs (health service utilization data from the Institute for Clinical Evaluative Sciences data repository), and patient-level cost of recovery (Ambulatory Home Care Record). A linear mixed model will be used to assess the effects of the intervention on the primary outcome, with an a priori contrast of weekly average worst pain intensity upon movement to evaluate the primary endpoint of pain at 8 weeks postoperation. We will also examine the incremental cost of the intervention compared to usual care using a regression model to estimate the difference in expected health care costs between groups.

Results: Study start-up is underway and usability testing is scheduled to begin in the fall of 2016.

Conclusions: Given our experience, dedicated industry partners, and related RCT infrastructure, we are confident we can make a lasting contribution to improving the care of seniors who undergo CaVS.

(JMIR Res Protoc 2016;5(3):e149) doi: 10.2196/resprot.5763

\section{KEYWORDS}

technology-enabled self-management; remote automated external monitoring; usability testing; randomized controlled trial 


\section{Introduction}

\section{Background}

Cardiac and vascular surgeries (CaVS) are performed on seniors [1] to improve survival and health-related quality of life (HRQL). Unfortunately, chronic postsurgical pain (CPSP), delayed detections of hemodynamic compromise, complications, and related poor functional status are major problems for substantial numbers of recovering patients [1]. This reflects the inadequacy of current systems for patient monitoring after CaVS, both on hospital surgical wards and at home. The current approach (eg, manually checking vital signs every 8-12 hours on postsurgical wards) results in thousands of cases of delayed detection of hemodynamic compromise (eg, low blood pressure and hypoxia) leading to severe complications (eg, myocardial infarction and stroke) [2] and drastically reduced HRQL. To tackle this problem, our aim is to refine and test the effectiveness of the eHealth-enabled service delivery intervention, TecHnology-Enabled remote monitoring and Self-MAnagemenT_-VIsion for patient EmpoWerment following Cardiac and VasculaR surgery (THE SMArTVIEW CoVeRed), which combines remote automated monitoring, education, and self-management training to optimize recovery in seniors undergoing CaVS, internationally.

\section{Population, Challenges, Gaps, and Inefficiencies to be Addressed}

\section{Overview}

Collectively as an innovation community we have completed, or are conducting, prospective outcome studies with $>65,000$ surgical patients, including CaVS patients [3-12]. Based upon the collective research and literature syntheses [13-15], CaVS can be currently characterized by several clinical inefficiencies, resulting in the key challenges discussed in the following sections.

\section{Chronic Postsurgical Pain and Related Consequences}

CaVS surgeries affect pain-sensitive structures as they invade muscle and visceral tissues, and involve the harvesting and manipulation of vessels. Such surgical tissue insults lead to pathological nervous system changes, collectively known as sensitization [16] — a function of neuronal modifiability [17]. Sensitization increases pain sensitivity (ie, hyperalgesia), augments the normal duration (ie, hyperpathia) and amplitude of pain, and results in abnormal interpretation of nonpainful stimuli as painful (ie, allodynia) [16]. In all cases, CPSP is, in part, a function of unrelieved acute postoperative (postop) pain that involves a transition phase [18] by virtue of these pathological mechanisms. In our review of 26 studies $(n=2033$; mean age 65.1 years) across 15 countries, CPSP prevalence following CaVS [11,12,18-41] ranged from 17-56\%. The 2013 Canadian prospective Cardiac (CARD) pain study $(n=1010)$ [11] reported more modestly varying CPSP prevalence rates of $40 \%, 22 \%$, and $17 \%$ at 3, 6, and 12 months following surgery, respectively; pain was most commonly located along the sternal incision and saphenous vein harvesting sites. But other studies have reported 1-year CPSP prevalence rates as high as $39 \%$ [39] and 45\% [40]. Rates of CPSP following vascular surgery are similar in range $(25 \%)$, with moderate to severe pain typically presenting along the femoropopliteal bypass tunnel [42].

The deleterious consequences of CPSP in CaVS-amidst divergent surgical populations - are well-known, with numerous studies reporting associations of CPSP with poor HRQL and depressive disorder [11,12,18-43]. We meta-analyzed available data [11,25,26,29,32,33,35] (see Multimedia Appendix 1) and found that among seniors who undergo CaVS, there is a statistically and clinically significant relationship between acute postop pain and CPSP development (standardized mean difference $0.28 ; 95 \%$ CI $0.12-0.44$ ) (see Table 1). This emphasizes the decades of research [44-53] which indicate that $\mathrm{CaVS}$ patients have erroneous pain and pain medication beliefs that obstruct acute postop pain management. In 2004, Watt-Watson et al [46] found that up to $83 \%$ of CaVS patients do not ask for pain medication when requiring it and that, on average, $<35 \%$ of prescribed analgesic dosages are routinely administered [46]. Current studies indicate that this unfortunate scenario remains unchanged. Cogan et al [53] recently found, for example, that $36 \%$ of CaVS patients believed that "pain medication should be spared until the pain is very severe" and $20 \%$ believed that "good patients do not speak of their pain." A gap revealed from this meta-analysis regarding CPSP was that unrelieved acute postop pain requires more effective intervention. A solution to this gap is that postop education, support, and acute pain monitoring and management at home are needed to prevent transition from acute postop pain to CPSP. 
Table 1. Meta-analysis: Differences in acute postoperative pain scores between those who do and do not develop chronic postsurgical pain.

\begin{tabular}{llll}
\hline Study & $\begin{array}{l}\text { Standardized mean difference } \\
\text { (SE) }\end{array}$ & $\begin{array}{l}\text { Weight } \\
(\%)\end{array}$ & $\begin{array}{l}\text { Standardized mean difference inverse variance random effects } \\
(95 \% \text { CI })\end{array}$ \\
\hline Choiniere et al 2014 [11] & $0.14(0.04)$ & 24.2 & $0.14(0.06$ to 0.22$)$ \\
King et al 2008 [25] & $0.07(0.11)$ & 17.3 & $0.07(-0.15$ to 0.29$)$ \\
Lahtinen et al 2006 [26] & $0.13(0.06)$ & 22.7 & $0.13(0.02$ to 0.25$)$ \\
Lee et al 2010 [35] & $0.96(0.39)$ & 3.8 & $0.96(0.19$ to 1.74$)$ \\
Steegers et al 2007 [29] & $0.86(0.17)$ & 12.3 & $0.86(0.53$ to 1.19$)$ \\
van Gulik et al 2011 [33] & $0.31(0.17)$ & 12.6 & $0.31(-0.02$ to 0.63$)$ \\
van Gulik et al 2012 [32] & $0.27(0.25)$ & 7.1 & $0.27(-0.25$ to 0.79$)$ \\
Total & N/A & N/A & $0.28(0.12$ to 0.44$)$ \\
\hline
\end{tabular}

${ }^{\mathrm{a}} \mathrm{N} / \mathrm{A}$ : not applicable.

\section{Undetected Hemodynamic Compromise}

CaVS are among the highest-risk surgeries and are associated with substantial postop morbidity and mortality. Following an immediate postop period of intensive care unit (ICU) hemodynamic surveillance, vital signs monitoring after ICU discharge is lacking. Most patients on surgical wards will have vital signs evaluated once per 4-12 hours [54,55]. Such limited in-hospital monitoring - followed by no daily monitoring at home-is significantly associated with poor clinical outcomes. For example, in a study from the Cleveland Clinic [56], nurses blinded to continuous pulse oximetry for monitoring peripheral oxygen saturation $\left(\mathrm{SpO}_{2}\right)$ assessed their postop patients $(\mathrm{n}=594)$ according to normal practice and detected a $5 \%$ incidence of hypoxemia $\left(\mathrm{SpO}_{2}<90 \%\right)$. Blindly captured study oximetry, however, detected that $37 \%$ of patients had one or more continuous episodes of hypoxemia for $\geq 1$ hour, and that $10 \%$ of patients had at least one continuous episode ( $\geq 1$ hour) of hypoxemia where $\mathrm{SpO}_{2}$ was $<85 \%$ [56]. Given that hypoxemia for $>5$ minutes is associated with increased risk of myocardial ischemia, suboptimal monitoring on surgical wards elevates risks for patients. Studies have also demonstrated that continuous electrocardiographic ST segment monitoring after surgery can identify asymptomatic ischemia that is independently associated with myocardial infarction [57-59]. A study of postop ST segment depression followed 151 consecutive patients undergoing major vascular surgery and assessed for postop myocardial ischemia [57]. Approximately $85 \%$ of patients who suffered postop cardiac events had preceding long-duration ST segment depressions [57]. These data suggest that remote, continuous, noninvasive ST segment monitoring systems can identify impending cardiac events much sooner than the usual practice of checking vital signs manually every 4-12 hours. The same is true for cardiac postop arrhythmias. The incidence of atrial fibrillation, in particular, is $20-40 \%$ after cardiac surgery, with even higher rates (30-50\%) after valvular surgery [60-62]. While most patients spend the first 12-24 hours after surgery in the ICU, $70 \%$ of postop atrial fibrillation occurs over the first 4 days following surgery, suggesting that many occurrences will be missed on surgical wards [63]. This common scenario is risk elevating, given that atrial fibrillation imposes a three-fold increase in hypotension and stroke $[64,65]$.
Data from large randomized controlled trials (RCTs) also suggest that blood pressure is a particularly important independent predictor of postop cardiac complications and death. The PeriOperative ISchemic Evaluation (POISE) trial [4] randomized 8351 patients to extended-release metoprolol (mean age 68.9 years) or placebo (mean age 69.1 years). Along with a reduction in myocardial infarction, a clinically significant increase in hypotension with metoprolol use was found (hazard ratio [HR] 1.55 ; 95\% CI 1.38-1.74). Overall, clinically significant hypotension is associated with the largest population-attributable risk for perioperative death and perioperative stroke [4]. Following POISE, POISE-2 was an international RCT of 10,010 patients with, or at risk of, vascular disease undergoing noncardiac surgery, including vascular surgery [5]. Analyses demonstrated that clinically important hypotension was an independent predictor of subsequent risk of myocardial infarction during 30-day follow-up (adjusted HR 1.37; 95\% CI 1.16-1.62) [5]. A gap revealed from this analysis was that current monitoring of patients after $\mathrm{CaVS}$ is inadequate, with significant harm resulting from undetected postoperative hypoxemia, arrhythmia, and hypotension. A solution to this gap is remote automated noninvasive postoperative monitoring, for 30 days following discharge, to enhance detection of hemodynamic compromise and reduce adverse event risk.

\section{Surgical Site Infections}

CaVS options are changing, with many patients choosing percutaneous coronary interventions (PCIs) to address vasculature blockages. This results in those undergoing $\mathrm{CaVS}$ manifesting disease that is either too advanced or too complicated for PCI. As such, CaVS patients-often with multiple comorbidities - are at high risk for surgical site infections (SSIs). In England, for example, SSIs occurred in $4.4 \%$ of patients $(n=29,144)$ who underwent coronary artery bypass grafting and $2.2 \%$ of patients $(n=7256)$ who underwent vascular surgery-in National Health Service hospitals from April 2008 to March 2013 [66]. The median time to infection identification was 12 days and 11 days after cardiac and vascular surgery, respectively [66]. A recent systematic review-57 studies-has corroborated the commonality of these infection rates and that SSIs, furthermore, have major consequences including mortality, repeated surgical procedures, hospital readmissions, and health-related economic burden [67]. 
Evidence from established daily postoperative surveillance systems in the United States suggests that daily wound monitoring can prevent SSI progression-superficial/incisional to deep wound/organ/space [68]. A gap revealed from this analysis is that postop SSIs often manifest at home following discharge and are potentially preventable [69]. A solution to this gap would be daily postop wound monitoring for early detection of, and to prevent progression of, SSIs that require hospitalization.

\section{Hospital Readmissions and Summary of Key Issues}

Not only are CaVS among the highest-risk surgeries, they are associated with high rates of hospital readmission. A 2014 prospective, multicenter cohort study-10 centers, 5185 patients-in Canada and the United States reported the rate of all-cause 30-day readmission following cardiac surgery at $18.7 \%$ [69]. Recent data (2014) from a large US registry $(\mathrm{N}=11,246)$ showed comparable rates of 30-day unplanned readmissions among major vascular surgery patients: $15.7 \%$, infrainguinal bypass [70]. Our particular focus on the aforementioned issues is due to the unequivocal association with poor postoperative functional recovery resulting in CPSP [11,12,18-41]; adverse cardiac events due to hemodynamic compromise [54-59]; and high rates of hospital readmission due to infection $[66,69]$. Postoperative infection, for example, is the most common reason for readmission in Canada following cardiac surgery $(17.1 \%)$ [69]. Other important recovery challenges for seniors, requiring intervention, include psychological morbidity (eg, anxiety and depression) [71-77] and medication reconciliation [78].

\section{Proposed eHealth Innovation-Enabled Care Delivery Program}

\section{Intervention in Canada and the United Kingdom}

This project is being undertaken in Canada and the United Kingdom because (1) the gaps and inefficiencies following CaVS are similar and (2) implementations of eHealth innovations require attention to agile/scalable designs which can be realized through efficient (ie, parallel) integration and effectiveness testing across two health systems.

\section{Targeting Seniors Recovering From Cardiac and Vascular Surgery}

Guided by the Integrated Vascular Health Blueprint for Ontario [79] and the UK Department of Health Cardiovascular Disease Outcomes Strategy [80], our aim is health service integration. The fragmented nature of cardiac/vascular care threatens the sustainability of health systems due to inefficiencies and waste. Given that factors associated with poor recovery are common to both sets of CaVS patients, we are aligned with the Canadian Vascular Health Coalition strategy—see page 7 of the Integrated Vascular Health Blueprint for Ontario [79]—of mapping and implementing more integrated ways of addressing cardiac and vascular disease-related burden.

\section{Partnership Process and Technology Partners}

Initial discussions have centered on eHealth Innovation Partnership Program objectives, CaVS recovery challenges, and potential partners' orientation to improving patient experience, willingness to codesign, and their match with desired partner criteria. Further discussions reviewed respective technology innovations and desired scope of involvement. As a result of this process, we are fortunate to be working with Philips Canada, QoC Health, XAHIVE, and mPath. These partners are drivers of innovation, ranging from small to medium enterprises, to a multinational organization.

\section{Guiding Principles, Work to Date, and Patient-Oriented Approach}

The intervention has been designed according to Patients First: Action Plan for Health Care [81]. Grounded in commitment to efficiency and integration of care, the following tenets of Patients First serve as our guiding principles: (1) Improve access: provide faster access to the right care by removing barriers to full scope of practice and coordinating care, (2) Connect patients to services: deliver integrated care that is home based when possible, (3) Protect public health care system: innovate based on evidence and capacity to engage patients, and (4) Inform: provide education and transparency. With Patients First as our framework, our leadership team and technology partners jointly applied for, and secured, competitive seed funding from the Michael G DeGroote Institute for Pain Research and Care at McMaster University. With these funds, a 2-day, international SMArTVIEW meeting was held for the purposes of intervention codesign, systems integration planning, and change management/scalability plan development. A professional facilitation company, Guiding Star Communications, led us through structured patient journey mapping and analysis. Divided into working groups — each with scientists; clinicians; CaVS patient representatives; engineers; and information technology, policy, and knowledge translation experts-we worked from stems of real CaVS cases to map the typical senior patient's recovery journey, based on experience. We then engaged in facilitated analysis of what "must change." Once "must change" items were distilled and validated by patient representatives, the technology partners showcased their evidence-based innovations for change. Using consensus techniques, we mapped partners' solutions to "must change" items in a codesign of the SMArTVIEW intervention. Three subgroups worked intensively on systems integration.

\section{Intervention Program, Technologies, and Effectiveness}

\section{Overview}

SMArTVIEW is an eHealth-enabled service delivery program-based on existing implementable technology and validated interventions-which combines remote monitoring, education, and self-management training (see Figure 1). The following review of SMArTVIEW components as a whole identifies key members of the health care team as well as key phases and technology enablers. 
Figure 1. The Self-MAnagemenT_-VIsion for patient EmpoWerment (SMArTVIEW) eHealth-enabled service delivery program. ECG: electrocardiogram.
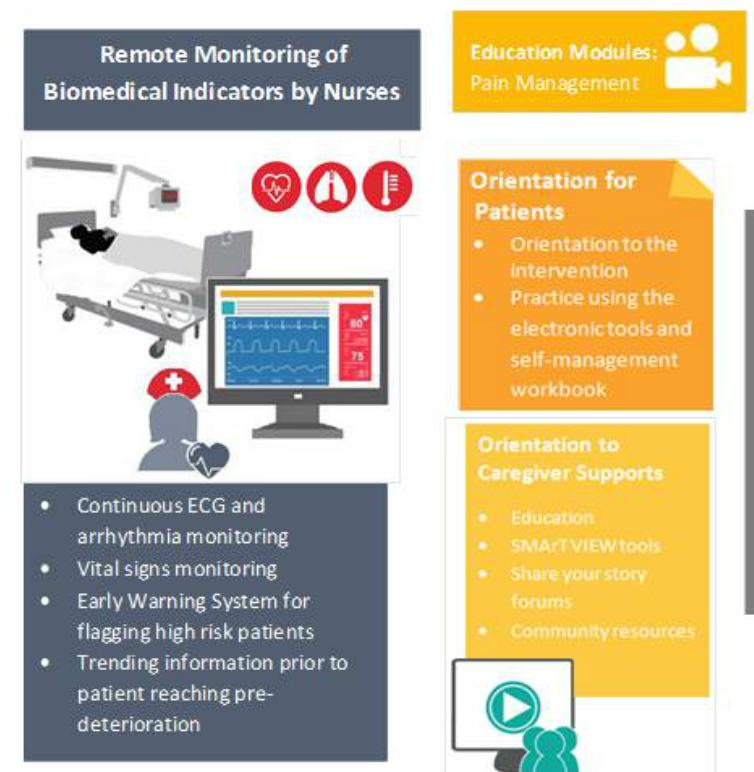

Stage 1: On Surgical Ward
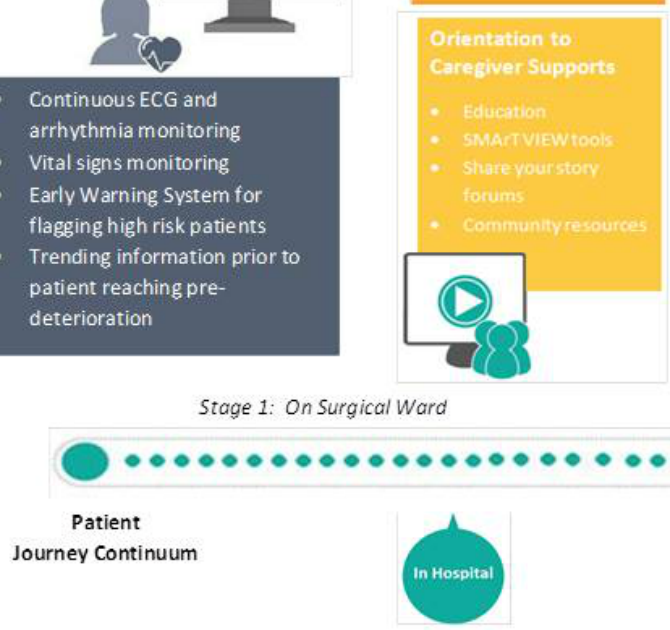

\section{Health Professionals Involved, Phases, and Technology Enablers}

Multiple clinicians are involved in seniors' circles of care in the hospital and the community. Successful implementation, however, requires centralized coordination. Therefore, the "SMArTVIEW Nurse" (SVN), a registered nurse with SVN training, is central. SMArTVIEW is a two-stage intervention program. Stage 1 supports seniors after CaVS in hospital on surgical wards post-ICU, with a view to seamless transition, while Stage 2 supports patients at home during the first 8 weeks of recovery (see Figure 1). Across stages, our clinical technology enablers include Philips' IntelliVue Guardian [82] and Transition to Ambulatory Care (eTrAC) Program [83], and QoC's Engagement Platform [84].

\section{Stage 1}

Stage 1 includes remote automated postoperative monitoring (Protect) and pain management education (Protect, Inform).

\section{Monitoring}

On the ward, remote monitoring will be implemented by the SVN via Philips' IntelliVue Guardian early warning system, which includes a centrally located monitor, a portable spot check monitor, and four lightweight cableless devices worn by the patient, with connectivity via short range radio and hotspot transmitters. The four devices are as follows: (1) MX40,a telemetry pack for 8-lead continuous electrocardiogram monitoring; (2) Acquire $\mathrm{SpO}_{2}$, a wrist-worn device applied to the index finger, which provides continuous $\mathrm{SpO}_{2}$ saturation

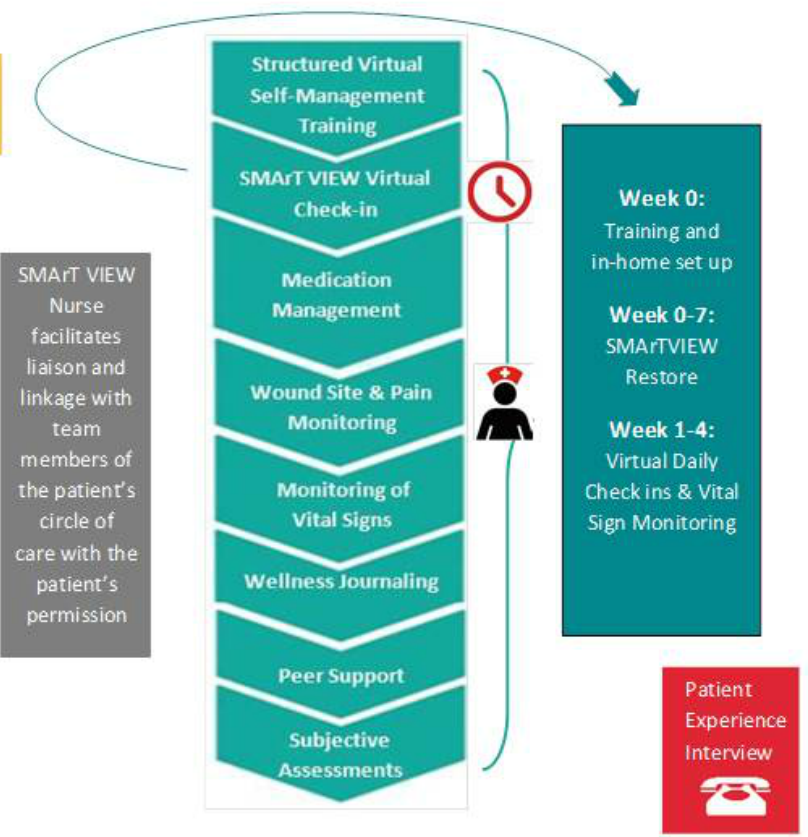

Stage 2: Post-Discharge (8 weeks)

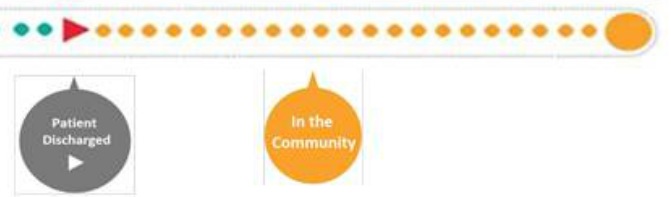

values under various artifact conditions, including motion and low perfusion, as well as pulse rate; (3) Acquire Blood Pressure, a noninvasive blood pressure cuff worn on the brachial aspect of the arm; and (4) Acquire Respiration Pod, a small patch-like device, attached to the left costal arch of the patient's chest, which derives respiration rate and patient posture via 3D accelerometer [82]. Receiving data from each device, IntelliVue Guardian software employs a deterioration notification algorithm to facilitate early intervention. This algorithm automates hospital early warning score (EWS) systems, normally performed manually by clinicians. EWSs track vital sign deviations from normal and trigger increasing attention to care, proportional to the deviation. By virtue of automation, IntelliVue Guardian efficiently verifies the accuracy of vital signs data by repeating measurements at customized intervals [82]. If early signs of deterioration are detected, IntelliVue Guardian will inform the SVN via mobile device. Moreover, clinicians on the ward are able to visualize EWS on the central monitor and spot check monitor, which is kept at the patient's bedside. As identified previously, remote automated monitoring is needed to identify undetected hemodynamic compromise and allow for early intervention to prevent adverse events following CaVS; IntelliVue Guardian provides a comprehensive, evidence-based solution [85] to meet this need.

\section{Education}

Education (Inform) is critical to prevent transition from acute postop pain to CPSP. To empower seniors to know how to communicate their postop pain experience and understand options for pain management (Protect), we employ, on ward 
day 2, Watt-Watson et al's Pain Relief After Surgery educational intervention [46]. Adapted as an animated video module, Pain Relief After Surgery is a 20-minute education tool, validated for CaVS patients-comprehension level: Grade 6-and designed to address common misbeliefs preventing patients from asking for improved pain relief. Content also emphasizes the individuality of pain responses and the importance of good pain relief for optimal recovery at home. RCT evidence supports the effectiveness of Pain Relief After Surgery for reducing pain-related interference during recovery as well as misbeliefs about analgesics [46]. In conjunction with Philips' eTrAC program, this video module will be issued to the patient on ward day 2 .

\section{Stage 2}

Stage 2 includes SVN hospital-to-home remote monitoring and support and self-management training.

\section{Hospital-to-Home Remote Monitoring and Support}

The eTrAC program is a tablet-based solution that combines clinical software for effective care management with Bluetooth-enabled, patient-monitoring devices measuring $\mathrm{SpO}_{2}$, blood pressure, temperature, blood glucose, and weight [83]. Philips eTrAC allows clinicians to monitor discharged (ie, at-home) patients' vital signs status from the hospital (Protect), and then prioritize them for required interventions (eg, signs of sepsis evident) based upon a combination of customized/standardized intervention rules [83]. eTrAC also features customizable, interactive patient symptom and self-report surveys to inform postoperative support and management. SMArTVIEW-specific surveys include postop daily symptoms, wound monitoring, sleep, nutrition, medication, quality of life, and patient satisfaction. Interactive modules assisting patient orientation to the system are also included. The clinician interface for the eTrAC program is eCare Coordinator (eCC), a cloud-based software tool designed to maximize efficiency through risk prioritization - patients are assigned overall scores calculated from weighted scores of self-report surveys, measurements, issues, risk of readmission, and discharge date if within the last 30 days. The overall score generated allows clinicians to manage large patient populations by triaging their interventions based on potential patient need (ie, those with the highest scores are seen first). Through eCC, clinicians can remotely manage patients, view and interpret results (eg, vital signs and symptom and reflexive surveys), follow up and intervene as needed, conduct video visits with patients, and document all patient interventions and observations.

The SVN will employ the eTrAC program to facilitate daily virtual check-ins and counseling, daily vital signs monitoring and triage, and review of interactive symptom and reflexive surveys (Access, Inform, Protect, Connect) [83].

\section{Self-Management Training}

As with Stage 1, we are committed in Stage 2, combining improved monitoring with education and support that empowers seniors to proactively prevent transition to CPSP and prevent poor functional recovery. As a team we are experienced in the development/testing of self-management models for people with coronary artery disease [86-88], other forms of chronic illness [89,90], and CPSP [91]. In conjunction with postoperative monitoring and support, participants will engage in SMArTVIEW Restore. Restore is a virtual self-management program, to be delivered in 2-hour sessions weekly, over a 7-week period, from week 0 (week of discharge) to week 6 postoperation (at home).

Figure 2 presents an overview of the Restore curriculum, based on seniors' CaVS recovery needs identified during patient journey mapping, as well as lessons learned from our previous self-management experience [86-91]. Both content and process elements of Restore are grounded in the fear-avoidance beliefs model [92], which shows how catastrophic pain perceptions can lead to fear, hypervigilance, avoidance, disability, and depression. The curriculum is designed to provide patients with requisite cognitive, emotional, and behavioral skills to manage their postop pain experience in a productive and positive way, leading to optimal functioning. Restore will be run on a time-release basis; interactive features will include weekly recovery goal setting, interactive reflexive activities, wellness journaling, a peer support forum, and a gratitude "wall."

Both the online interactive elements as well as self-efficacy-enhancing features of Restore will be adapted specifically from the Coventry University Help to Overcome Problems Effectively (HOPE) and Internet-based (iHOPE) programs. As one of the first self-management interventions combining positive psychology and cognitive behavioral therapy theory, iHOPE includes evidence-based and positive psychological activities such as goal setting, action planning, identifying personal strengths, scheduling pleasant activities, mindfulness, relaxation training, and reviewing successes [93]. Feasibility trials have shown that HOPE has the potential to improve important quality-of-life outcomes for people living with and affected by a range of long-term conditions [94,95]. Recently, Coventry University and Macmillan Cancer Support - the United Kingdom's leading charity and source of cancer support-tested a Web-based version of HOPE (iHOPE) for cancer survivors, comprised of six interactive Web-based sessions, which combine cancer self-management information and education with self-monitoring tools, worksheets, audioand video-based materials, interactive goal setting and gratitude "walls," and social networking via email and discussion forums. Feasibility trial results showed that participants' depression, anxiety, fatigue, fear of cancer returning, positive mental well-being, hope, and gratitude all significantly improved [95]. Participants' course experience and usability ratings were high, with all of the participants willing to recommend iHOPE to other users [95].

To facilitate our adaptation of iHOPE interactive elements, QoC Health's Engagement Platform will be leveraged to customize and integrate the validated modules (ie, feature sets) from their existing platforms and to develop customized modules to transform Restore from concept to a codesigned interactive digital solution. QoC will apply the principles of user interface and user experience design to create a user-friendly and intuitive solution with reduced interface friction. An iterative, user-centered design framework featuring participatory design will be used to develop the Web-based solution, which will be 
optimized for tablet. QoC will facilitate codesign development sessions with our patient representatives to ensure Restore is aligned with their recovery needs and that it considers their technical capabilities (eg, digital literacy and technology-savvy level) and design preferences. The cognitive load on users will be minimized by abating unnecessary decisions/steps and inconsistencies in the interface. To offer the end user an enhanced e-learning experience throughout Restore, the design will feature "digital resting spaces." This will be achieved by applying the concepts of e-learning (eg, pacing and quantity and diversity of content) and using the principles of white space to balance content and segregate sections.

In summary, our technology partners are cutting-edge eHealth innovators for change with evidence-based solutions. For example, Philips' IntelliVue Guardian has been shown to significantly increase timely clinical response in hospital, based on abnormal vital signs detection, as well as survival after rapid response treatment [85]. Emerging evidence also suggests that solutions developed through QoC's Engagement Platform are feasible, acceptable, and beneficial to postop patients and surgical teams $[96,97]$.

Figure 2. The Self-MAnagemenT_-VIsion for patient EmpoWerment (SMArTVIEW) Restore curriculum. CaVS: cardiac and vascular surgery.

\begin{tabular}{|c|c|c|c|c|c|c|c|}
\hline Module & Week 0 & Week1 & Week2 & Week3 & Week4 & Week5 & Week6 \\
\hline $\begin{array}{l}\text { Orientation to the SMArTVIEW self- } \\
\text { management system }\end{array}$ & • & & & & & & \\
\hline $\begin{array}{l}\text { Overview of post-operative self- } \\
\text { management }\end{array}$ & - & & & & & & \\
\hline Listening to your heart & & - & - & - & - & - & - \\
\hline Managing your post-operative wounds & & - & - & - & - & - & - \\
\hline Gratitude diary & & - & • & - & - & - & - \\
\hline $\begin{array}{l}\text { Weight tracking for fluid management after } \\
\text { surgery }\end{array}$ & & - & - & - & - & - & - \\
\hline Solution-focused goal setting and action planning & & - & - & - & - & - & - \\
\hline Managing your medications & & - & - & • & • & - & • \\
\hline Share your story forum for caregivers & & - & - & • & - & - & - \\
\hline Getting a good night's sleep after CaVS surgery & & - & - & & & & \\
\hline $\begin{array}{l}\text { Instilling hope and other positive emotions after } \\
\text { CaVS surgery }\end{array}$ & & & - & & & & \\
\hline $\begin{array}{l}\text { Dealing with depression and difficult emotions } \\
\text { during recovery }\end{array}$ & & & - & & & & \\
\hline Staying active during recovery & & & - & & & & \\
\hline Solution-focused goal feedback & & & - & & & & \\
\hline Preventing falls during recovery \& Vitamin $D$ & & & - & & & & \\
\hline Mindfulness & & & - & & & & \\
\hline $\begin{array}{l}\text { Avoiding chronic pain and pain misbeliefs after } \\
\text { Cavs }\end{array}$ & & & $\bullet$ & & & & \\
\hline Better breathing after cardiac surgery & & & - & & & & \\
\hline Wellness journaling & & & - & - & - & - & - \\
\hline Pacing and energy conservation & & & & - & & & \\
\hline Healthy eating $\mathrm{I}$, general introduction & & & & - & - & - & \\
\hline Relaxation & & & & - & & & \\
\hline Prority setting & & & & - & & & \\
\hline Fear avoidance & & & & & - & & \\
\hline Physical activity and exercise & & & & & - & - & - \\
\hline Healthy eating II, nutrition recovery & & & & & - & & \\
\hline Stress management & & & & & - & & \\
\hline Medication usage during recovery & & & & & & - & \\
\hline Weight management & & & & & & - & \\
\hline Communication skills & & & & & & - & \\
\hline Sexuality and intimacy & & & & & & - & \\
\hline $\begin{array}{l}\text { Prevent setbacks and dealing with setbacks } \\
\text { when they occur during recovery }\end{array}$ & & & & & & & - \\
\hline $\begin{array}{l}\text { Communication skills I, working with your health } \\
\text { care professional and organization }\end{array}$ & & & & & & & - \\
\hline Moving forward, leading a happy, flourishing life & & & & & & & - \\
\hline
\end{tabular}

\section{Systems Integration}

SMArTVIEW deploys a highly integrated "system of systems." Multiple decentralized and heterogeneous subsystems, with operational and managerial independence, are required to provide our end-to-end SMArTVIEW solution. Our end goal for clinical data management is to ensure that the right information is provided to the right person, at the right time. We have consulted extensively with our information technology and clinical informatics experts to leverage existing assets through systems architecture, as opposed to duplicating functionality or existing data. Moreover, our technology partners' solutions meet Health Level 7 [98] industry standards for seamless connection and bidirectional data exchange with 
our hospital information and electronic medical record systems. We will also use application programming interfaces for the extraction of data. We are confident we can achieve integrated exchange of information, from hospital to home.

\section{Privacy and Data Aggregation}

Our additional partners, XAHIVE and mPath, serve as our chief stewards of privacy and data aggregation, respectively. With privacy paramount, we espouse a "privacy by design" approach [99]. Privacy will be role based, highly configurable, and will include the entire circle of care, including formal and informal caregivers and supports by patient consent. To achieve these objectives, we will employ XAHIVE's secure communication service platform, extensible using a custom off-the-shelf model. The XAHIVE communication protocol does not require servers in order to operate, nor does it require specific hardware devices; these two factors give our team an advantage in the arena of scalability of our deployments. XAHIVE will interface with hospital information systems at both sites-Canada and the United Kingdom - in order to realize (1) consistent security across all communication touch points in the SMArTVIEW system, and (2) a clear chain of custody on the privacy of data per legislative requirements. SMArTVIEW involves multiple "moving parts" that will generate data about recovering seniors' status and behavior via peripheral devices. Additionally, the solutions we use will generate and aggregate clinical measurements in discrete locations. Third-party data sets (eg, health services utilization data) will also be accessed, allowing for correlations to be made beyond the scope of our integrated systems. There are multiple considerations in the way data is aggregated (eg, efficiency of architecture, reduction of redundancy, and optimization of data accessibility). As leading experts, mPath will govern our data aggregation practices.

\section{Scalability}

With scalability central to our vision, all partner solutions are at technology readiness Level 9, with next to zero time to solution required. Our scalability report will include documentation of (1) unforeseen issues as they arise and problem solving strategies, (2) patient and SVN experience, and (3) results of our comprehensive econometrics evaluation plan, distilled into a projected model of total cost of 1-year SMArTVIEW patient throughput, based on site surgical volumes.

\section{Evaluation Plan Objectives}

The objectives of the evaluation plan are to refine SMArTVIEW (Phase 1) and conduct an RCT to examine its effectiveness.

\section{Settings}

Both evaluation plan phases will take place at Hamilton Health Sciences, Hamilton, Canada, and Liverpool Heart and Chest Hospital, the United Kingdom; the coordinating center is the Population Health Research Institute, Hamilton, Canada.

\section{Methods}

\section{Phase 1: Usability Testing}

\section{Participants}

Included participants will be (1) aged $\geq 65$ years, (2) undergoing major CaVS with predicted admission $>48$ hours, and (3) able to read, speak, and understand English such that reflexive intervention surveys generated by eTrAC can be completed (ie, Grade 6 reading level). Those excluded will have planned postop admission or readmission to a nursing home or long-term care facility.

\section{Design and Procedures}

\section{Overview}

Rogers' methods for usability testing [100] will guide SMArTVIEW refinement in the first 9 months. Patients and clinicians will engage in two cycles of focus groups and usability testing at each site, as described in the following sections.

\section{Focus Groups}

Two focus groups, one at each site, will each be conducted with 5 CaVS patients and 5 SVNs via an adapted semistructured interview guide [101]. With well-established technology partner solutions (ie, applications and devices), our focus is refining overall system intervention flow and staging. After viewing still images of each SMArTVIEW stage, feedback will be elicited about (1) what is seen in each still, (2) expectations for engaging with the SVN and eTrAC solutions at each stage, (3) what each stage should accomplish, and (4) if conceptualization of SMArTVIEW aligns with participants' mental models of required tasks.

\section{Usability Testing}

High-fidelity user testing of SMArTVIEW, focused on intraoperability and flow of information, will involve a human factors analyst, a research assistant (RA) with design ethnography training, and the leadership team. Focus group findings will be embedded into test (ie, simulated) clinical scenarios, representing CaVS recovery issues. Using think-aloud $[102,103]$ protocols and task completion checklists, this usability testing cycle-conducted twice, once at each site-will have SVNs and patients rehearse all scenarios wherein information coming from either player can be communicated, via automated monitoring or self-report. Scheduled for 2 hours in the hospital and 2 hours in the patient's home soon after, but not on the same day, rehearsals will be observed by the human factors analyst and the RA. Through analysis of recorded usability testing data to identify patterns of use, areas of satisfaction or frustration, and system efficiencies and problems, the human factors analyst and the RA will determine actions for system refinement $[104,105]$. The entire cycle will be repeated, this time observing real-time-based interaction. 


\section{Phase 2: Randomized Controlled Trial}

\section{Methods}

\section{Trial Design}

Research questions to be addressed in a two-group, parallel-arm

Figure 3. Randomized controlled trial flow diagram. IWRS: Interactive Web Randomization System.

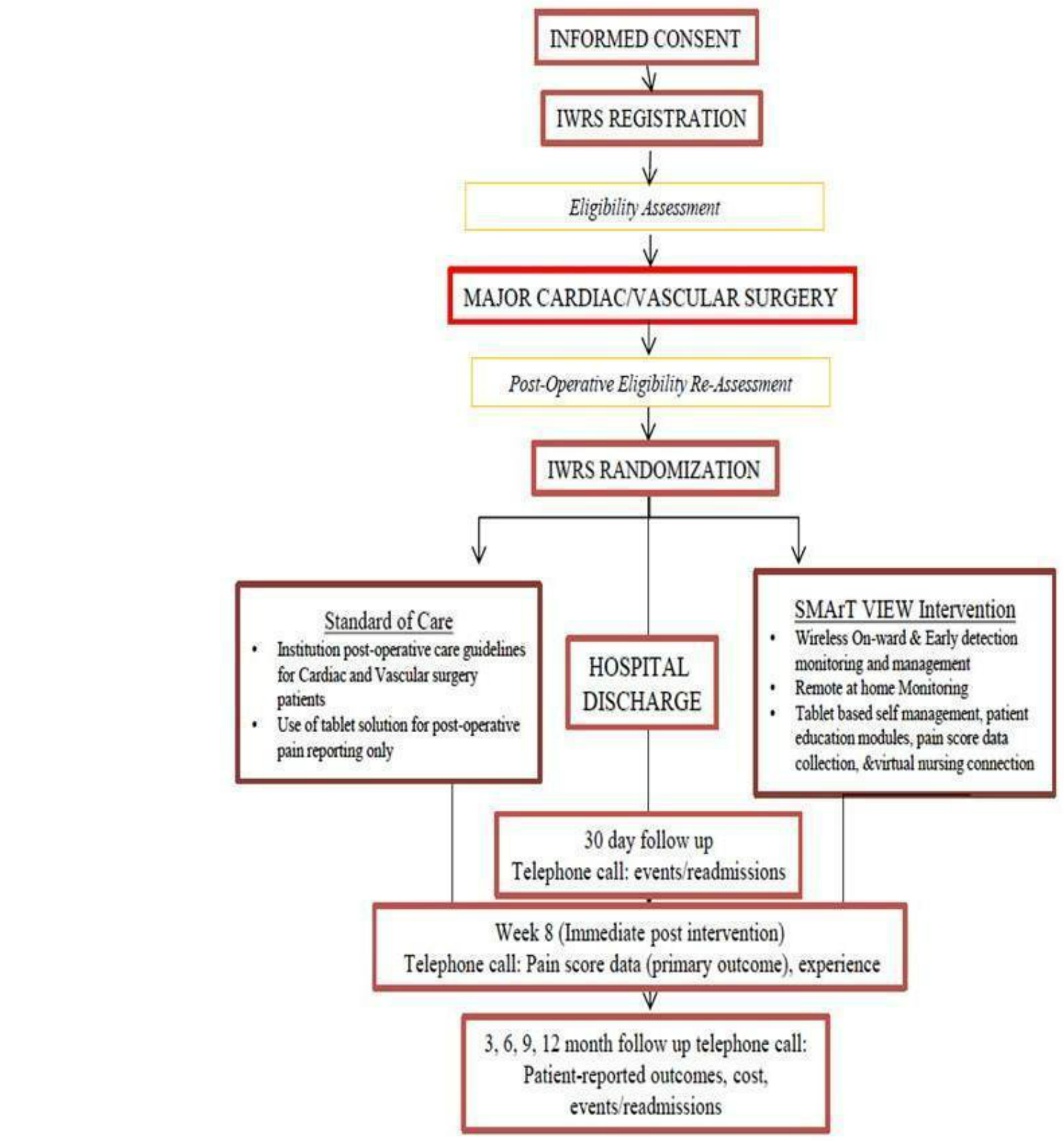

\section{Participants}

Participants will be included according to the inclusion/exclusion criteria outlined in Phase 1, with two additional exclusion criteria: (1) participation in Phase 1 and (2) positive Confusion Assessment Method (CAM) screening upon transfer to the surgical ward.
RCT (see Figure 3) include effectiveness of the intervention to (1) improve postop pain at 30 days (primary outcome) and (2) composite of major postop complications related to hemodynamic compromise, HQRL, depressive symptoms, health service utilization costs, and patient-level cost of recovery (secondary outcomes).

\section{The Self-Management_-Vision for Patient Empowerment Intervention}

The components of the SMArTVIEW intervention will be as described under the Intervention Program, Technologies, and Effectiveness section. The intervention delivery protocol, by stage, is presented in Table 2. This protocol features SVN support from the surgical ward 24 hours/day, 7 days/week. 
Table 2. SMArTVIEW ${ }^{\mathrm{a}}$ intervention delivery protocol by stage.

\begin{tabular}{ll}
\hline Stages & Details \\
\hline $\begin{array}{l}\text { Stage 1: In hospital } \\
\text { IntelliVue Guardian setup } \\
\text { (ward day 1) }\end{array}$ & \\
& \\
& Upon transfer to the ward, the IntelliVue Guardian early warning system is established by \\
& the $S V N^{b}$ on duty, who connects patient to peripheral, cableless devices; establishes base- \\
& line/normal vital signs with spot check monitor; activates IntelliVue Guardian; and performs \\
& system checks every shift. \\
& The $S V N$ will receive alerts via mobile device; alerts will be set according to surgeon- \\
& sanctioned vital signs parameters programmed into IntelliVue Guardian, which allow for \\
tailoring of profiles for day or night, as well as pre-existing comorbid conditions (eg, atrial \\
fibrillation). \\
Upon alerts, SVN assessment, intervention, and escalation of care will be according to usual \\
hospital protocols.
\end{tabular}

Patient and family pain education and hospitalto-home orientation

(ward day 2)

Receipt of SMArTVIEW hospital-to-home package and skills rehearsal

(day prior to discharge)

\section{Stage 2: In the community}

\section{Setup (week 1 postdischarge)}

Patient monitoring and virtual check-ins (first 30 days postdischarge)

\section{SMArTVIEW-Restore}

(0 to 7 weeks postdischarge)
The SVN will facilitate a 2.5-hour hospital-to-home orientation session implemented at the convenience of the patient, supports (eg, family, friends, and caregivers), and clinical workflow.

This orientation will focus on the $\operatorname{eTrAC}^{\mathrm{c}}$ tablet-based applications, the PRAS ${ }^{\mathrm{d}}$ educational video, and Restore.

Following the orientation, the SVN will invite and answer questions.

On the day prior to discharge, patients will receive their hospital-to-home packages from the SVN, including eTrAC tablet-based solutions, instructions for monitoring vital signs at home, eTrAC 30-day application schedule for monitoring vital signs, SVN video visits, and daily recovery symptom and reflexive surveys.

Upon receipt of this hospital-to-home package, the SVN will facilitate a 30-minute checklistoriented rehearsal of all eTrAC features; the SVN will also invite and answer questions.

Philips' in-home installation team will work with the SVN to establish the Bluetooth-enabled vital signs monitoring system.

The SVN will then commence monitoring of all incoming data from eTrAC via eCC ${ }^{\mathrm{e}}$.

The SVN will perform daily 15 -minute virtual check-ins-eTrAC video visits—with patients at home from the hospital via eCC, per hospital-to-home package instructions.

Virtual check-ins will include review of priorities flagged in eCC, review of vital signs and symptom and reflexive survey data, postop pain assessment, and discussion of any patient/SVN concerns.

Issues identified-via eCC risk stratification or SVN assessment-that require intervention, but are out of the scope of SVN practice, will be escalated to the most responsible clinician.

During recovery, participants will engage the Restore time-release, self-guided, online curriculum (described previously). 


\begin{tabular}{ll}
\hline Stages & Details \\
\hline & $\begin{array}{l}\text { Restore is structured according to seven weekly asynchronous modules, consisting of two } \\
\text { to seven activities each. } \\
\text { Restore is designed to constitute 2-3 hours of online activity, weekly. }\end{array}$ \\
\hline
\end{tabular}

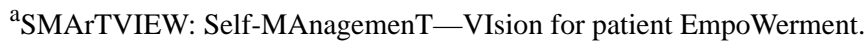

bSVN: SMArTVIEW Nurse.

cTrAC: Transition to Ambulatory Care.

${ }^{\mathrm{d}}$ PRAS: pain relief after surgery.

eCC: eCare Coordinator.

\section{Outcome Measures}

\section{Primary Outcome}

The primary outcome is worst postop pain intensity upon movement in the previous 24 hours-at 30 days after randomization-averaged across the previous 14 days. This will be assessed using the Brief Pain Inventory-Short Form (BPI-SF), which has well-established reliability and validity in surgical groups, including CaVS [15,106,107]. Common to studies with postop pain as a primary outcome [15,106,107], patients will report worst pain-intensity rating both upon rest and movement in the past 24 hours. The primary outcome of worst pain upon movement is a more reliable indicator of suboptimal pain management and pain-related interference with recovery-related activities than worst pain upon rest $[15,106,107]$.

\section{Secondary Outcomes}

\section{Postoperative Complications Related to Hemodynamic Compromise}

We will capture a composite of complications related to hemodynamic compromise up to 30 days postrandomization, including death, myocardial infarction, and nonfatal stroke. The number of events for the overall composite, as well as number of events per component within the composite, will be reported.

\section{All-Cause Mortality and Other Postoperative Complications}

All-cause mortality will be captured up to 1 year postrandomization. We will also monitor for new-onset atrial fibrillation and SSI up to 30 days postrandomization.

\section{Functional Status}

The Short-Form 12 version 2 (SF-12v2) is an established, reliable, and valid tool $[108,109]$ to measure functional status $[108,109]$. The SF-12v2 provides both physical component summary and mental component summary scores $[9,11,46,109]$.

\section{Depressive Symptoms}

The five-question version of the Geriatric Depression Scale (GDS-5) will be used to measure depressive symptoms. This tool is a well-validated instrument in the assessment of depression in hospitalized older adults, with high levels of sensitivity and specificity $[110,111]$.

\section{Chronic Postsurgical Pain}

Development of CPSP is defined [112] as (1) pain that developed after the surgical procedure, (2) being different from pain experienced before surgery, and (3) being present for at least 3 months. Patient responses in the affirmative to each of these questions indicate patients have developed CPSP. For patients who have developed CPSP, pain intensity and related interference with usual daily activities will be measured via the BPI-SF [106,107].

\section{Heath Service Utilization-Related Cost}

Data on hospital readmission and health care utilization and costs of health service utilization data from the Canadian arm of the trial will be linked with the health administrative Institute for Clinical Evaluative Sciences data repository. Administrative databases used to describe the health service utilization include (1) Registered Persons Database-demographics and vital statistics of all legal residents of Ontario, (2) Discharge Abstract Database-records of inpatient hospitalizations-from the Canadian Institute for Health Information (CIHI), (4) Ontario Health Insurance Plan Database_-physician billing claims, and (5) the National Ambulatory Care Reporting System-information on emergency department visits-from CIHI. In addition, to capture data on times spent on the portal by health providers (eg, pharmacists and nurses), costs of health providers' time will be captured in the system reporting. Costs of health providers' time on the portal will be calculated by multiplying the time with unit costs from standard costing sources in Ontario.

\section{Patient-Level Cost of Recovery}

The Ambulatory and Home Care Record (AHCR) [11,113-117] will be used to comprehensively measure patient-level cost of illness from a societal perspective (Canada and the United Kingdom). This approach gives equal consideration to health system costs and costs borne by patients and unpaid caregivers (eg, family members and friends). AHCR items can be categorized as publicly financed (eg, public sector paid resources) or privately financed care (eg, all out-of-pocket and third-party insurance payments, and time costs incurred by caregiver). Face validity and reliability of the AHCR is well-established in multiple groups, including CaVS patients [11,113-117].

\section{Baseline Measures to Inform Subgroup Analyses}

Aside from baseline clinical and demographic information, gender-based pain expectations [118] will be assessed to inform subgroup analyses as evidence suggests that gender-based pain expectations may lead to differences in the experience of pain and related response to interventions [118]. These expectations will be captured using the Gender Role Expectations of Pain (GREP) tool, which captures stereotypic attributions regarding 
pain endurance, pain sensitivity, and willingness to report pain. The GREP tool has been used in multiple pain investigations [118-123] with acceptable test-retest and internal consistency reliability [118].

Baseline digital literacy will also be assessed using an adapted version of the informational and instrumental support domains of the Patient-Reported Outcomes Measurement Information System (PROMIS) measures. This approach, previously pilot-tested with cardiovascular patients [124], employs five items to examine current level of engagement with mobile and digital technologies.

\section{Follow-Up}

The SVN will collect outcome data for intervention and control groups following random allocation through discharge. Once in the community, patients in both groups will record their BPI-SF pain scores daily for 8 weeks using the tablet-based solutions. Data on 30-day event rates (ie, major postop complications) and hospital readmissions for both groups will be collected by a blinded RA via telephone interview at 30 days postoperation. At 3, 6, 9, and 12 months, additional telephone interviews conducted by the RA will assess (1) functional status, (2) depressive symptoms, (3) CPSP, and (4) patient-level cost of recovery (ie, AHCR).

\section{Qualitative Data Collection}

To understand patient experience with CaVS recovery and involvement with the SMArTVIEW intervention, we will conduct telephone interviews with 60 patients and 60 primary support persons in the intervention and control groups and with all SVNs $(n=20)$ using a semistructured interview guide. The interviews will focus on perceptions of usability and ethical, social, and legal issues. Our sample size should ensure data saturation [125].

\section{Sample Size}

Assuming a two-sided type I error (alpha) of .05 and a standard deviation of 20 points in BPI-SF numeric rating scale scores (range 0-100), a total of 128 participants (ie, 64 individuals in each group) are required to provide $80 \%$ power to detect a minimally important difference of 10 points. This difference represents a moderate effect size (Cohen's $d=0.50$ ) [126]. Assuming a 10\% loss to follow-up, 144 total patients (or 72 per group) is required. We will use this sample size for each site, to allow for site-specific analyses with equal and sufficient power. If there is sufficient homogeneity between the Canadian and UK samples, the combined sample (eg, 256 patients with complete data) would provide $80 \%$ power to detect a difference in pain intensity scores of 8.6 points (Cohen's $d=0.43$ ), assuming a generous design effect [127] of 1.5 due to the clustering of participants within the site.

\section{Recruitment}

Strategies previously developed will be applied [3,6]; RAs will screen preoperative surgical patient lists daily. Anesthesia, $\mathrm{CaVS}$, and medicine services will contact the RAs for all CaVS admissions through emergency and new consultations. Eligible patients will be approached and invited. Patients providing informed consent will be registered via the Interactive Web Randomization System (IWRS), a 24-hour, central, computerized, secure (ie, password-protected), Web-based registration/randomization service at the Population Health Research Institute, and baseline data will be collected. Patients undergoing urgent surgeries will be approached postoperation.

\section{Randomization and Allocation}

Blocked randomization (ie, randomly assigned block sizes) will be used to achieve balanced allocation of intervention and control groups. The randomization allocation list will be prepared by Population Health Research Institute statisticians and integrated into the IWRS system. Upon transfer to the surgical ward (ie, post-ICU), the SVN will assess consented patients using the CAM. If CAM scores do not indicate cognitive impairment or delirium and the patient remains eligible, they will be randomly allocated by the IWRS.

\section{Feasibility}

Our technology partners have contributed equipment and personnel time, in-kind, such that we are able to intervene and follow up on 15 patients at one time per site throughout the study until 30 days follow-up, at which time equipment will be returned to each hospital site for cleaning and reset. Therefore, the RCT (Phase 2) will be executed in five serial, parallel waves of approximately 30 patients per site. In 2014, there were 2311 and 1974 CaVS performed at Hamilton Health Sciences, Canada, and the Liverpool Heart and Chest Hospital, the United Kingdom, respectively. Planned recruitment will occur at a rate feasible for SVN time and access to the surgical populations at both sites. Patients will be enrolled during a 3-week period, with the last week of each recruitment month available for additional patient registrations as needed to accommodate those not meeting postop eligibility. Each site will target recruitment of 14 cardiac and 16 vascular patients during 3 weeks of recruitment-10 patients per week, per site. Allowing for a $25 \%$ refusal rate, lost opportunities, and competing studies, this still provides access to 20 patients at Hamilton Health Sciences and 17 patients at the Liverpool Heart and Chest Hospital. Since participant recruitment is only limited by prototype availability, our proposed recruitment target and timeline is feasible and recruitment of 300 participants will be completed in 10 months' time.

\section{Data Analyses}

\section{Primary Analyses}

Table 3 summarizes all data analyses. Using the intent-to-treat principle [128], all patients will be included in the final analysis and according to the group to which they were randomly allocated. Descriptive statistics will be used to describe sample characteristics using measures of central tendency and dispersion for continuous factors, and frequencies and proportions for categorical factors. A two-sided significance level of .05 will be used for all inferential analyses. Statistical methods used will depend on the type and distribution of data for the outcome variable under study. If outcome data meet requirements for parametric statistics, a linear mixed model [129] will be used to assess the effects of the intervention on the primary outcome. An a priori contrast of the weekly average worst score for the BPI-SF numeric rating scale upon movement (previous 24 hours) 
will be used to evaluate the primary endpoint of acute postop pain at 30 days postrandomization.

Linear mixed models, using an autoregressive [130] covariance structure-allowing for correlations between measurements to decline as they are further apart in time-will be used to evaluate within-patient variation in patient-reported outcomes over 12 months of follow-up. Linear mixed models are a flexible and powerful approach to the analysis of data with a complex variance structure, such as correlated data [129-131]. Unlike traditional repeated-measures designs, these models do not require complete data on each patient and have increased statistical power [132]. Nonlinear mixed models will be used in the following cases: (1) if continuous data violate assumptions of normality [132] and (2) for categorical secondary outcomes (eg, adverse event). Chi-square tests of association will be used to assess the association between categorical secondary outcomes identified in the administrative data and intervention. Given that the data is derived from an RCT, complex modeling for these outcomes will not be performed, as potential confounders are considered to be adjusted for in the design. Finally, we will examine patterns of missing data and determine demographic and/or clinical characteristics that are related to missing data at each time point, and the potential impact on the primary findings.

\section{Secondary Analysis}

A secondary analysis will aim to establish the cumulative impact of the components of the intervention (eg, remote monitoring and self-management training) on outcomes and assess "digital retention" and sustained digital device usage in visual and time-sensitive analyses using an $\mathrm{N}$-of-1 design (see Table 3). $\mathrm{N}$-of-1 designs use a patient as their own control and can assess the impact of incremental changes with respect to the intervention with frequent and repeated measurements of the outcome variable of interest (ie, pain over time) and are particularly applicable to digital health and mobile phone-based clinical trials [133]. An N-of-1 design allows for association of causality to interventions in real time and direct methods to estimate individual treatment effects and variation per patient. Using the funnel approach, an individual patient is observed repeatedly to graphically demonstrate the variation in pain and HRQL over time [134].

\section{Subgroup Analyses}

Two types of separate subgroup analyses are planned to determine the impact of gender-based pain expectations and patient sex on intervention effectiveness (see Table 3 ):

1. Patients will be stratified into high versus low GREP scores. The primary analyses examining the effect of the intervention on the worst score for the BPI-SF numeric rating scale upon movement (previous 24 hours) will be conducted. An interaction term for GREP score (low versus high) and the group allocation will be incorporated into the analyses to determine if gender-based pain expectations are associated with differences in the effect of the intervention on the primary outcome. If a significant interaction is identified, the primary analysis in these two groups will be performed.
2. Similarly, interaction between the intervention and patient sex will be examined.

\section{Cost-Effectiveness Analyses}

The cost-effectiveness of implementing the intervention will be determined from two perspectives: (1) the Ministry of Health and Long-Term Care (MoHLTC) (Canada) and (2) society (Canada and the United Kingdom) (see Table 3). Separate analyses will be conducted from each perspective. MoHLTC costs will include costs associated with health service utilization over the study period (eg, hospitalization, emergency room visits, day surgery or procedure, laboratory services, outpatient visits, prescription drugs, and home care services from the Institute of Clinical Evaluative Sciences). Time that health providers (eg, pharmacists) spent on the SMArTVIEW portal will be calculated by multiplying the time with unit costs from standard costing sources in Ontario. From the societal perspective, costs will include those from the MoHLTC perspective, including costs incurred to patients and family members (eg, travel cost and productivity loss), which will be captured through the AHCR.

The first economic analysis outcome is the incremental cost of the intervention compared to usual care. We will analyze the total cost as a dependent variable, using a regression model to estimate the difference in expected health care cost between the two groups. The intervention will be the primary independent variable and the regression model will adjust for potential confounding variables. In theory, an ordinary least squares model produces unbiased estimates even if the data are skewed [135,136]; however, additional estimation methods (eg, generalized linear models) and different uncertainty methods (eg, parametric and nonparametric bootstrapping) will be explored to facilitate investigation of the impact of various cost assumptions.

As a secondary cost objective, we will compare the cost and quality-adjusted life years (QALYs) between the two groups using the net benefit regression framework (see Table 3). QALY is a preference-based utility measure of HRQL, as perceived by the patient, that incorporates both length of life and quality of life into a single measure [137,138]. We aim to determine the incremental net benefit of interventions versus usual care. To estimate QALYs gained, we will convert SF-12v2 data collected to utility scores using a validated algorithm. We will also estimate the incremental cost per QALY gained. A cost-effectiveness acceptability curve $(95 \% \mathrm{CI})$ will be used to characterize the uncertainty of our findings [139].

\section{Uptake of Technology}

Data on uptake of the SMArTVIEW intervention will be used to explain differences in the outcome measures, determine patterns of use to predict outcomes, and identify users who may require escalated care. Session frequency (ie, times the technology is accessed) and session length (ie, length of time users interact with the technology) [140] will be determined via daily metrics of both device and application use. During Phase 1, mPath will identify all key actions of SMArTVIEW to generate a template for relevant data collection at a granular, individual user level. 
Table 3. Summary of outcomes, hypotheses, measures, and methods of analysis.

\begin{tabular}{|c|c|c|c|c|}
\hline Analyses & Outcome & Hypothesis & Outcome measure & Method of analysis \\
\hline \multicolumn{5}{|l|}{$\begin{array}{l}\text { Primary } \\
\text { outcome }\end{array}$} \\
\hline & $\begin{array}{l}8 \text {-week worst postop pain inten- } \\
\text { sity upon movement score in the } \\
\text { past } 24 \text { hours }\end{array}$ & Intervention $>$ control & $\begin{array}{l}\text { Measured by Brief Pain Inventory- } \\
\text { Short Form }\left(B P I-S F^{a}\right)\end{array}$ & $\begin{array}{l}\text { Linear mixed model or nonlinear } \\
\text { mixed models (if assumptions of } \\
\text { normality are violated) }\end{array}$ \\
\hline & Functional status & Intervention $>$ control & Short-Form 12 version 2 & $\begin{array}{l}\text { Linear mixed model or nonlinear } \\
\text { mixed models (if assumptions of } \\
\text { normality are violated) }\end{array}$ \\
\hline & Depressive symptom scores & Intervention $>$ control & $\begin{array}{l}\text { Five-question version of the Geri- } \\
\text { atric Depression Scale }\end{array}$ & $\begin{array}{l}\text { Linear mixed model or nonlinear } \\
\text { mixed models (if assumptions of } \\
\text { normality are violated) }\end{array}$ \\
\hline & $\begin{array}{l}\text { Postop complications related to } \\
\text { hemodynamic compromise }\end{array}$ & Intervention $>$ control & Myocardial infarction and stroke & Nonlinear mixed models \\
\hline & $\begin{array}{l}\text { Other relevant postop complica- } \\
\text { tions }\end{array}$ & Intervention $>$ control & $\begin{array}{l}\text { Surgical site infection, presence of } \\
\text { CPSP }^{b}\end{array}$ & Nonlinear mixed models \\
\hline & $\begin{array}{l}\text { Heath service utilization-related } \\
\text { cost }\end{array}$ & Intervention $>$ control & $\begin{array}{l}\text { Linked with health administrative } \\
\text { Institute for Clinical Evaluative } \\
\text { Sciences data repository }\end{array}$ & $\begin{array}{l}\text { Linear mixed model or nonlinear } \\
\text { mixed models (if assumptions of } \\
\text { normality are violated) }\end{array}$ \\
\hline & Patient-level cost of recovery & Intervention $>$ control & $\begin{array}{l}\text { Ambulatory and Home Care } \\
\text { Record }\end{array}$ & $\begin{array}{l}\text { Linear mixed model or nonlinear } \\
\text { mixed models (if assumptions of } \\
\text { normality are violated) }\end{array}$ \\
\hline \multicolumn{5}{|l|}{$\begin{array}{l}\text { Subgroup } \\
\text { outcomes }\end{array}$} \\
\hline & All outcomes & $\begin{array}{l}\text { Effect will differ by } \\
\text { GREP }^{c} \text { scores (low versus } \\
\text { high) }\end{array}$ & $\begin{array}{l}\text { Worst postop pain intensity upon } \\
\text { movement score in the past } 24 \\
\text { hours measured by BPI-SF numer- } \\
\text { ic rating scale }\end{array}$ & Interaction test \\
\hline
\end{tabular}

${ }^{\mathrm{a} B P I-S F}$ : Brief Pain Inventory-Short Form.

${ }^{\mathrm{b}}$ CPSP: chronic postsurgical pain.

${ }^{\mathrm{c}}$ GREP: Gender Role Expectations of Pain.

\section{Qualitative Analyses}

\section{Qualitative Description}

Data will be digitally recorded, transcribed verbatim, and managed in NVivo 11 (QSR International). Concepts that relate to the usability and value of the intervention will be coded [141] and reviewed by investigators to resolve differences and minimize biases [141]. Revisions to the interview guide and codebook will reflect emerging themes.

\section{Critical Qualitative Analysis}

To reveal the ethical, legal, and social implications of the intervention, we will apply methods used successfully in previous research [142]. Following this, data will be re-examined using four bioethical concepts-relational autonomy, care, social justice, and privacy - to draw out the normative implications of the intervention which are sensitive to ethical issues common to at-home care for seniors [143]. A retroductive process will be used that involves moving between observations and concepts and allows the interplay between individuals' lives and larger social and contextual forces to be understood $[144,145]$. The four concepts will not be used simply as containers to categorize data uncritically to aid in the social and ethical analysis of the data. Rigor will be maintained by keeping a reflexive journal and audit trail [141] and ensuring that the purpose of the research, theoretical assumptions, and method of data analysis are congruent [146].

\section{Controls for Bias}

To limit sampling bias, a recruitment schedule randomly generated to ensure representation from each surgical group will be used. Contamination should not exist between groups as we will control who interacts with the SVN and intervention features. Those allocated to the intervention group will be asked not to share their tablets or demonstrate application features to any peers assigned to the control group. To evaluate 
cointervention, we will track participant receipt of any monitoring or recovery support-related interventions, outside of expected usual care up to 8 weeks postoperation. RAs responsible for outcome data collection will be separated from randomization procedures, will have no permitted access to IWRS, will not be involved in intervention delivery, and will be blinded to group allocation. An event adjudication committee responsible for adjudication of all clinical outcome data will be blinded to randomized allocation. The team has extensive experience with assiduous follow-up procedures to minimize losses to follow-up.

\section{Knowledge Translation}

Integrated knowledge translation strategies will continue to involve stakeholder groups during the project. As part of integrated and end-of-grant knowledge translation, stakeholders will assist in interpreting findings, identifying key results, and reviewing and revising the end-of-grant knowledge translation plan at a final meeting for review of investigator results. End-of-grant knowledge translation goals-generate interest, discussion, and awareness; impart knowledge; and inform research-will be addressed via tailored implementation strategies.

\section{Results}

Study start-up is underway and usability testing is scheduled to begin in the fall of 2016 .

\section{Discussion}

THE SMArTVIEW, CoVeRed innovation community brings together an international, dedicated group of well-known clinical and eHealth researchers; health economists; clinicians; administrators; patient representatives; engineers, information technology, and clinical informatics experts; as well as leaders in the arenas of health policy, big data and data aggregation, bioethics, knowledge translation, and privacy. Collectively, we possess the requisite skills, experience, and track record to execute the proposed evaluation, disseminate what we learn, and plan for diffusion of innovation.

We are actively engaged in systems integration and change management at both study sites. As a result of planned, shared stewardship of our vision, we have fostered a milieu of co-ownership and investment in SMArTVIEW usability and effectiveness testing. With respect to end-user engagement, we understand well from experience that innovation is not a linear process. We are committed to recursive coinnovation between "solutioner" and end users. Hence, corefinement of SMArTVIEW - via usability testing in context—was a key objective identified during team debriefing, following our patient journey mapping exercise. Akin to the use of "experimentation suites" in the industry sector, our process, as outlined within the Usability Testing section, will be to immerse with participants in high-fidelity rehearsal of SMArTVIEW activities in order to uncover ways we can refine our processes to optimize the experience of recovery for seniors following CaVS. Our team, including patient representatives, is organized into both content and governance committees (see Table 4).

In collaboration with our industry partners, Canadian and UK hospital sites, we are confident that we have the experience, expertise, infrastructure, and support to realize THE SMArTVIEW, CoVeRed. A copy of our Canadian Institutes of Health Research (CIHR) reviews can be found in Multimedia Appendix 2. 
Table 4. SMArTVIEW ${ }^{\mathrm{a}}$ team committees.

\begin{tabular}{|c|c|}
\hline Committee type & Committee name \\
\hline \multicolumn{2}{|l|}{ Content } \\
\hline & Clinical Transformation/Change Management \\
\hline & Clinical Monitoring \\
\hline & Patient Engagement and Experience \\
\hline & Economics \\
\hline & Knowledge Translation \\
\hline & Systems Integration \\
\hline & Self-Management \\
\hline & Clinician and $\mathrm{SVN}^{\mathrm{b}}$ Training \\
\hline & Ethics \\
\hline \multicolumn{2}{|l|}{ Governance } \\
\hline & Project Office Operations \\
\hline & International Operations \\
\hline & Steering \\
\hline & Outcomes Adjudication \\
\hline & External Safety \\
\hline & Efficacy and Monitoring \\
\hline & Substudy and Publications \\
\hline
\end{tabular}

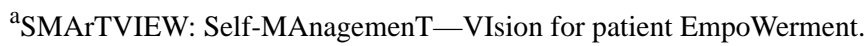

${ }^{\mathrm{b}} \mathrm{SVN}$ : SMarTVIEW Nurse.

\section{Acknowledgments}

This grant was funded by the Canadian Institutes of Health Research (grant no. 348440). In-kind industry support is provided by the following industry partners: Philips, QoC Health, XAHIVE, and mPath. Dr Michael McGillion holds the Heart and Stroke Foundation/Michael G DeGroote Endowed Chair in Cardiovascular Nursing. Our patient journey mapping process was supported with seed funding from the Michael G DeGroote Institute for Pain Research and Care at McMaster University.

The authors wish to acknowledge Ms Nancy Luck for her assistance with manuscript preparation. The authors also wish to acknowledge the collaboration of Melody Miles from the Hamilton Niagara Haldimand Brant Community Care Access Centre as well as Alison Paprika from the Institute for Clinical Evaluative Sciences. Finally, Janet Parr, Kay Ball, Graham Barker, Graham Densham, Sandra Gartz, and James Ace are patient representatives who provided considerable input into the design of the SMArTVIEW intervention.

\section{Conflicts of Interest}

In-kind industry support is provided by the following industry partners: Philips, QoC Health, XAHIVE, and mPath. The following authors are employed by Philips: Karsten Russell Wood, Michael Weber, Jolene McNeil, and Robyn Alpert. Sarah Sharpe is Co-Founder and shareholder, QoC Health; Sue Bhella is employed by QoC Health. David Mohajer is Co-Founder, Chief Executive Officer, and Vice President, XAHIVE; Sem Ponnambalem is Co-Founder, Chief Operating Officer, and President, XAHIVE. Naeem Lakhani and Rabia Khan are Co-Founders, mPath.

\section{Multimedia Appendix 1}

Approach to meta-analysis.

[PDF File (Adobe PDF File), 27KB-Multimedia Appendix 1]

\section{Multimedia Appendix 2}

Canadian Institutes of Health Research (CIHR) reviews. 
[PDF File (Adobe PDF File), 313KB-Multimedia Appendix 2]

\section{References}

1. McGillion M, Turner A, Carroll SL, Furze G, Busse J, Lamy A. Optimising self-management to reduce chronic pain and disability after cardiac surgery. Br J Cardiol 2015;22:38. [doi: 10.5837/bjc.2015.011]

2. Gill NP, Wright B, Reilly CS. Relationship between hypoxaemic and cardiac ischaemic events in the perioperative period. Br J Anaesth 1992 May;68(5):471-473. [Medline: 1642934]

3. Vascular Events In Noncardiac Surgery Patients Cohort Evaluation (VISION) Study Investigators, Devereaux PJ, Chan MT, Alonso-Coello P, Walsh M, Berwanger O, et al. Association between postoperative troponin levels and 30-day mortality among patients undergoing noncardiac surgery. JAMA 2012 Jun 6;307(21):2295-2304. [doi: 10.1001/jama.2012.5502] [Medline: 22706835]

4. POISE Study Group, Devereaux PJ, Yang H, Yusuf S, Guyatt G, Leslie K, et al. Effects of extended-release metoprolol succinate in patients undergoing non-cardiac surgery (POISE trial): A randomised controlled trial. Lancet 2008 May 31;371(9627):1839-1847 [FREE Full text] [doi: 10.1016/S0140-6736(08)60601-7] [Medline: 18479744]

5. Devereaux PJ, Mrkobrada M, Sessler DI, Leslie K, Alonso-Coello P, Kurz A, POISE-2 Investigators. Aspirin in patients undergoing noncardiac surgery. N Engl J Med 2014 Apr 17;370(16):1494-1503. [doi: 10.1056/NEJMoa1401105] [Medline: 24679062]

6. McGillion M, Arthur HM, Natarajan M, Cook A, Gunn E, Watt-Watson J, et al. Nonischemic chest pain following successful percutaneous coronary intervention at a regional referral centre in southern Ontario. Can J Cardiol 2012;28(2 Suppl):S60-S69. [doi: 10.1016/j.cjca.2011.10.017] [Medline: 22424285]

7. Lamy A, Devereaux PJ, Prabhakaran D, Taggart DP, Hu S, Paolasso E, et al. Off-pump or on-pump coronary-artery bypass grafting at 30 days. N Engl J Med 2012 Apr 19;366(16):1489-1497. [doi: 10.1056/NEJMoa1200388] [Medline: 22449296]

8. Lamy A, Devereaux PJ, Prabhakaran D, Hu S, Piegas LS, Straka Z, et al. Rationale and design of the coronary artery bypass grafting surgery off or on pump revascularization study: A large international randomized trial in cardiac surgery. Am Heart J 2012 Jan;163(1):1-6. [doi: 10.1016/j.ahj.2011.10.007] [Medline: 22172429]

9. Le Manach Y, Perel A, Coriat P, Godet G, Bertrand M, Riou B. Early and delayed myocardial infarction after abdominal aortic surgery. Anesthesiology 2005 May;102(5):885-891. [Medline: 15851872]

10. Devereaux PJ, Xavier D, Pogue J, Guyatt G, Sigamani A, Garutti I, POISE (PeriOperative ISchemic Evaluation) Investigators. Characteristics and short-term prognosis of perioperative myocardial infarction in patients undergoing noncardiac surgery: A cohort study. Ann Intern Med 2011 Apr 19;154(8):523-528. [doi: 10.7326/0003-4819-154-8-201104190-00003] [Medline: 21502650]

11. Choinière M, Watt-Watson J, Victor JC, Baskett RJ, Bussières JS, Carrier M, et al. Prevalence of and risk factors for persistent postoperative nonanginal pain after cardiac surgery: A 2-year prospective multicentre study. CMAJ 2014 Apr 15;186(7):E213-E223 [FREE Full text] [doi: 10.1503/cmaj.131012] [Medline: 24566643]

12. Parry M, Watt-Watson J, Hodnett E, Tranmer J, Dennis C, Brooks D. Pain experiences of men and women after coronary artery bypass graft surgery. J Cardiovasc Nurs 2010;25(3):E9-E15. [doi: 10.1097/JCN.0b013e3181cd66be] [Medline: 20386237]

13. Macrae WA. Chronic post-surgical pain: 10 years on. Br J Anaesth 2008 Jul;101(1):77-86 [FREE Full text] [doi: 10.1093/bja/aen099] [Medline: 18434337]

14. Bach S, Noreng MF, Tjéllden NU. Phantom limb pain in amputees during the first 12 months following limb amputation, after preoperative lumbar epidural blockade. Pain 1988 Jun;33(3):297-301. [Medline: 3419837]

15. Katz J, Seltzer Z. Transition from acute to chronic postsurgical pain: Risk factors and protective factors. Expert Rev Neurother 2009 May;9(5):723-744. [doi: 10.1586/ern.09.20] [Medline: 19402781]

16. Basbaum A, Bushnell MC, Devor M. Pain: Basic mechanisms. In: Castro-Lopes J, Raja S, Schmelz M, editors. Pain 2008 - An Updated Review: Refresher Course Syllabus. Glasgow, Scotland: IASP Press; 2008:3-10.

17. Wolf CJ, Salter M. Plasticity and pain. In: McMahon SB, Koltzenburg M, editors. Wall and Melzack's Textbook of Pain. 5th edition. Philadelphia, PA: Elsevier Churchill Livingstone; 2006:91-105.

18. Bar-El Y, Gilboa B, Unger N, Pud D, Eisenberg E. Skeletonized versus pedicled internal mammary artery: Impact of surgical technique on post CABG surgery pain. Eur J Cardiothorac Surg 2005 Jun;27(6):1065-1069. [doi:

10.1016/j.ejcts.2005.02.016] [Medline: 15896618]

19. Bruce J, Drury N, Poobalan AS, Jeffrey RR, Smith WC, Chambers WA. The prevalence of chronic chest and leg pain following cardiac surgery: A historical cohort study. Pain 2003 Jul;104(1-2):265-273. [Medline: 12855337]

20. Eisenberg E, Pultorak Y, Pud D, Bar-El Y. Prevalence and characteristics of post coronary artery bypass graft surgery pain (PCP). Pain 2001 May;92(1-2):11-17. [Medline: 11323122]

21. Gjeilo KH, Klepstad P, Wahba A, Lydersen S, Stenseth R. Chronic pain after cardiac surgery: A prospective study. Acta Anaesthesiol Scand 2010 Jan;54(1):70-78. [doi: 10.1111/j.1399-6576.2009.02097.x] [Medline: 19681771]

22. Ho SC, Royse CF, Royse AG, Penberthy A, McRae R. Persistent pain after cardiac surgery: An audit of high thoracic epidural and primary opioid analgesia therapies. Anesth Analg 2002 Oct;95(4):820-823, table of contents. [Medline: $\underline{12351251]}$ 
23. Jensen MK, Andersen C. Can chronic poststernotomy pain after cardiac valve replacement be reduced using thoracic epidural analgesia? Acta Anaesthesiol Scand 2004 Aug;48(7):871-874. [doi: 10.1111/j.0001-5172.2004.00437.x] [Medline: 15242432]

24. Kalso E, Mennander S, Tasmuth T, Nilsson E. Chronic post-sternotomy pain. Acta Anaesthesiol Scand 2001 Sep;45(8):935-939. [Medline: 11576042]

25. King KM, Parry M, Southern D, Faris P, Tsuyuki RT. Women's Recovery from Sternotomy-Extension (WREST-E) study: Examining long-term pain and discomfort following sternotomy and their predictors. Heart 2008 Apr;94(4):493-497. [doi: 10.1136/hrt.2007.117606] [Medline: 17639091]

26. Lahtinen P, Kokki H, Hynynen M. Pain after cardiac surgery: A prospective cohort study of 1-year incidence and intensity. Anesthesiology 2006 Oct;105(4):794-800. [Medline: 17006079]

27. Mailis A, Umana M, Feindel CM. Anterior intercostal nerve damage after coronary artery bypass graft surgery with use of internal thoracic artery graft. Ann Thorac Surg 2000 May;69(5):1455-1458. [Medline: 10881822]

28. Meyerson J, Thelin S, Gordh T, Karlsten R. The incidence of chronic post-sternotomy pain after cardiac surgery--A prospective study. Acta Anaesthesiol Scand 2001 Sep;45(8):940-944. [Medline: 11576043]

29. Steegers MA, van de Luijtgaarden A, Noyez L, Scheffer GJ, Wilder-Smith OH. The role of angina pectoris in chronic pain after coronary artery bypass graft surgery. J Pain 2007 Aug;8(8):667-673. [doi: 10.1016/j.jpain.2007.04.007] [Medline: 17569594]

30. Taillefer M, Carrier M, Bélisle S, Levesque S, Lanctôt H, Boisvert A, et al. Prevalence, characteristics, and predictors of chronic nonanginal postoperative pain after a cardiac operation: A cross-sectional study. J Thorac Cardiovasc Surg 2006 Jun;131(6):1274-1280. [doi: 10.1016/j.jtcvs.2006.02.001] [Medline: 16733157]

31. Ucak A, Onan B, Sen H, Selcuk I, Turan A, Yilmaz AT. The effects of gabapentin on acute and chronic postoperative pain after coronary artery bypass graft surgery. J Cardiothorac Vasc Anesth 2011 Oct;25(5):824-829. [doi:

10.1053/j.jvca.2010.11.017] [Medline: 21232979]

32. van Gulik L, Ahlers SJ, van de Garde EM, Bruins P, van Boven WJ, Tibboel D, et al. Remifentanil during cardiac surgery is associated with chronic thoracic pain $1 \mathrm{yr}$ after sternotomy. Br J Anaesth 2012 Oct;109(4):616-622 [FREE Full text] [doi: 10.1093/bja/aes247] [Medline: 22831889]

33. van Gulik L, Janssen LI, Ahlers SJ, Bruins P, Driessen AH, van Boven WJ, et al. Risk factors for chronic thoracic pain after cardiac surgery via sternotomy. Eur J Cardiothorac Surg 2011 Dec;40(6):1309-1313. [doi: 10.1016/j.ejcts.2011.03.039] [Medline: 21561786]

34. Wiklund L, Johansson M, Bugge M, Rådberg LO, Brandup-Wognsen G, Berglin E. Early outcome and graft patency in mammary artery grafting of left anterior descending artery with sternotomy or anterior minithoracotomy. Ann Thorac Surg 2000 Jul;70(1):79-83. [Medline: 10921686]

35. Lee W, Yan Y, Jensen MP, Shun S, Lin Y, Tsai T, et al. Predictors and patterns of chronic pain three months after cardiac surgery in Taiwan. Pain Med 2010 Dec;11(12):1849-1858 [FREE Full text] [doi: 10.1111/j.1526-4637.2010.00976.x] [Medline: 21040435]

36. Garland R, Frizelle FA, Dobbs BR, Singh H. A retrospective audit of long-term lower limb complications following leg vein harvesting for coronary artery bypass grafting. Eur J Cardiothorac Surg 2003 Jun;23(6):950-955. [Medline: 12829071]

37. Herlitz J, Brandrup-Wognsen G, Evander MH, Caidahl K, Hartford M, Karlson BW, et al. Symptoms of chest pain and dyspnoea during a period of 15 years after coronary artery bypass grafting. Eur J Cardiothorac Surg 2010 Jan;37(1):112-118. [doi: 10.1016/j.ejcts.2009.06.018] [Medline: 19648023]

38. Momeni M, De Kock M, Lavand'homme P, Watremez C, Van Dyck M, Baele P. Abnormal sensations evoked over the chest and persistent peri-incisional chest pain after cardiac surgery. Acta Anaesthesiol Belg 2010;61(2):55-62. [Medline: 21155438]

39. Onan B, Onan IS, Kilickan L, Sanisoglu I. Effects of epidural anesthesia on acute and chronic pain after coronary artery bypass grafting. J Card Surg 2013 May;28(3):248-253. [doi: 10.1111/jocs.12086] [Medline: 23461638]

40. van Leersum NJ, van Leersum RL, Verwey HF, Klautz RJ. Pain symptoms accompanying chronic poststernotomy pain: A pilot study. Pain Med 2010 Nov;11(11):1628-1634 [FREE Full text] [doi: 10.1111/j.1526-4637.2010.00975.x] [Medline: 21044253]

41. Routledge FS, Tsuyuki RT, Hervas-Malo M, LeBlanc P, McFetridge-Durdle JA, King KM. The influence of coronary artery bypass graft harvest site on women's pain, functional status, and health services utilization throughout the first post-operative year: A longitudinal study. Int J Nurs Stud 2009 Aug;46(8):1054-1060. [doi: 10.1016/j.ijnurstu.2009.02.003] [Medline: 19269633]

42. Greiner A, Rantner B, Greiner K, Kronenberg F, Schocke M, Neuhauser B, et al. Neuropathic pain after femoropopliteal bypass surgery. J Vasc Surg 2004 Jun;39(6):1284-1287 [FREE Full text] [doi: 10.1016/j.jvs.2004.02.003] [Medline: 15192570]

43. Markman PL, Rowland MA, Leong JY, Van Der Merwe J, Storey E, Marasco S, et al. Skeletonized internal thoracic artery harvesting reduces chest wall dysesthesia after coronary bypass surgery. J Thorac Cardiovasc Surg 2010 Mar;139(3):674-679. [doi: 10.1016/j.jtcvs.2009.03.066] [Medline: 19775705] 
44. Casida JM, Davis JE, Shpakoff L, Yarandi H. An exploratory study of the patients' sleep patterns and inflammatory response following cardiopulmonary bypass (CPB). J Clin Nurs 2014 Aug;23(15-16):2332-2342. [doi: 10.1111/jocn.12515] [Medline: 24329980]

45. Zimmerman L, Barnason S, Brey BA, Catlin SS, Nieveen J. Comparison of recovery patterns for patients undergoing coronary artery bypass grafting and minimally invasive direct coronary artery bypass in the early discharge period. Prog Cardiovasc Nurs 2002;17(3):132-141. [Medline: 12091762]

46. Watt-Watson J, Stevens B, Katz J, Costello J, Reid GJ, David T. Impact of preoperative education on pain outcomes after coronary artery bypass graft surgery. Pain 2004 May;109(1-2):73-85. [doi: 10.1016/j.pain.2004.01.012] [Medline: 15082128]

47. Gjeilo KH, Klepstad P, Wahba A, Lydersen S, Stenseth R. Chronic pain after cardiac surgery: A prospective study. Acta Anaesthesiol Scand 2010 Jan;54(1):70-78. [doi: 10.1111/j.1399-6576.2009.02097.x] [Medline: 19681771]

48. Gunnarsdottir S, Serlin RC, Ward S. Patient-related barriers to pain management: The Icelandic Barriers Questionnaire II. J Pain Symptom Manage 2005 Mar;29(3):273-285. [doi: 10.1016/j.jpainsymman.2004.06.015] [Medline: 15781178]

49. Leegaard M, Nåden D, Fagermoen MS. Postoperative pain and self-management: Women's experiences after cardiac surgery. J Adv Nurs 2008 Sep;63(5):476-485. [doi: 10.1111/j.1365-2648.2008.04727.x] [Medline: 18727750]

50. Khan R, Skapinakis P, Ahmed K, Stefanou DC, Ashrafian H, Darzi A, et al. The association between preoperative pain catastrophizing and postoperative pain intensity in cardiac surgery. Pain Med 2012 Jun 15;13(6):820-827. [Medline: 22568812]

51. Watt-Watson J, Stevens B, Garfinkel P, Streiner D, Gallop R. Relationship between nurses' pain knowledge and pain management outcomes for their postoperative cardiac patients. J Adv Nurs 2001 Nov;36(4):535-545. [Medline: 11703548]

52. Watt-Watson J. Misbeliefs about pain. In: Watt-Watson J, Donovan M, editors. Pain Management: Nursing Perspective. St. Louis, MO: Mosby; 1992:36-58.

53. Cogan J, Ouimette MF, Vargas-Schaffer G, Yegin Z, Deschamps A, Denault A. Patient attitudes and beliefs regarding pain medication after cardiac surgery: Barriers to adequate pain management. Pain Manag Nurs 2014 Sep;15(3):574-579. [doi: 10.1016/j.pmn.2013.01.003] [Medline: 23485659]

54. Leuvan $\mathrm{CH}$, Mitchell I. Missed opportunities? An observational study of vital sign measurements. Crit Care Resusc 2008 Jun;10(2):111-115. [Medline: 18522524]

55. McGain F, Cretikos MA, Jones D, Van Dyk S, Buist MD, Opdam H, et al. Documentation of clinical review and vital signs after major surgery. Med J Aust 2008 Oct 6;189(7):380-383. [Medline: 18837681]

56. Sun Z, Sessler DI, Dalton JE, Devereaux PJ, Shahinyan A, Naylor AJ, et al. Postoperative hypoxemia is common and persistent: A prospective blinded observational study. Anesth Analg 2015 Sep;121(3):709-715. [doi: 10.1213/ANE.0000000000000836] [Medline: 26287299]

57. Landesberg G, Luria MH, Cotev S, Eidelman LA, Anner H, Mosseri M, et al. Importance of long-duration postoperative ST-segment depression in cardiac morbidity after vascular surgery. Lancet 1993 Mar 20;341(8847):715-719. [Medline: 8095624]

58. Mangano DT, Browner WS, Hollenberg M, London MJ, Tubau JF, Tateo IM. Association of perioperative myocardial ischemia with cardiac morbidity and mortality in men undergoing noncardiac surgery. The Study of Perioperative Ischemia Research Group. N Engl J Med 1990 Dec 27;323(26):1781-1788. [doi: 10.1056/NEJM199012273232601] [Medline: 2247116]

59. Mangano DT, Hollenberg M, Fegert G, Meyer ML, London MJ, Tubau JF, et al. Perioperative myocardial ischemia in patients undergoing noncardiac surgery--I: Incidence and severity during the 4 day perioperative period. The Study of Perioperative Ischemia (SPI) Research Group. J Am Coll Cardiol 1991 Mar 15;17(4):843-850. [Medline: 1999618]

60. Echahidi N, Pibarot P, O'Hara G, Mathieu P. Mechanisms, prevention, and treatment of atrial fibrillation after cardiac surgery. J Am Coll Cardiol 2008 Feb 26;51(8):793-801 [FREE Full text] [doi: 10.1016/j.jacc.2007.10.043] [Medline: 18294562]

61. Zaman AG, Archbold RA, Helft G, Paul EA, Curzen NP, Mills PG. Atrial fibrillation after coronary artery bypass surgery: A model for preoperative risk stratification. Circulation 2000 Mar 28;101(12):1403-1408 [FREE Full text] [Medline: 10736284]

62. Almassi GH, Schowalter T, Nicolosi AC, Aggarwal A, Moritz TE, Henderson WG, et al. Atrial fibrillation after cardiac surgery: A major morbid event? Ann Surg 1997 Oct;226(4):501-511; discussion 511-513. [Medline: 9351718]

63. Aranki SF, Shaw DP, Adams DH, Rizzo RJ, Couper GS, VanderVliet M, et al. Predictors of atrial fibrillation after coronary artery surgery. Current trends and impact on hospital resources. Circulation 1996 Aug 1;94(3):390-397 [FREE Full text] [Medline: $\underline{8759081]}$

64. Maesen B, Nijs J, Maessen J, Allessie M, Schotten U. Post-operative atrial fibrillation: A maze of mechanisms. Europace 2012 Feb;14(2):159-174 [FREE Full text] [doi: 10.1093/europace/eur208] [Medline: 21821851]

65. Maisel WH, Kuntz KM, Reimold SC, Lee TH, Antman EM, Friedman PL, et al. Risk of initiating antiarrhythmic drug therapy for atrial fibrillation in patients admitted to a university hospital. Ann Intern Med 1997 Aug 15;127(4):281-284. [Medline: 9265427] 
66. Public Health England. Surveillance of Surgical Site Infections in NHS hospitals in England, 2012/2013. London, UK: Public Health England; 2013. URL: https://www.gov.uk/government/uploads/system/uploads/attachment data/file/364319/ SSI annual report 2012 to 13 final.pdf [accessed 2016-05-02] [WebCite Cache ID 6hD5oQBS5]

67. Korol E, Johnston K, Waser N, Sifakis F, Jafri HS, Lo M, et al. A systematic review of risk factors associated with surgical site infections among surgical patients. PLoS One 2013;8(12):e83743 [FREE Full text] [doi: 10.1371/journal.pone.0083743] [Medline: 24367612]

68. Haley RW, Culver DH, White JW, Morgan WM, Emori TG, Munn VP, et al. The efficacy of infection surveillance and control programs in preventing nosocomial infections in US hospitals. Am J Epidemiol 1985 Feb;121(2):182-205. [Medline: 4014115]

69. Iribarne A, Chang H, Alexander JH, Gillinov AM, Moquete E, Puskas JD, et al. Readmissions after cardiac surgery: Experience of the National Institutes of Health/Canadian Institutes of Health Research cardiothoracic surgical trials network. Ann Thorac Surg 2014 Oct;98(4):1274-1280 [FREE Full text] [doi: 10.1016/j.athoracsur.2014.06.059] [Medline: 25173721]

70. Gupta PK, Fernandes-Taylor S, Ramanan B, Engelbert TL, Kent KC. Unplanned readmissions after vascular surgery. J Vasc Surg 2014 Feb;59(2):473-482 [FREE Full text] [doi: 10.1016/j.jvs.2013.09.002] [Medline: 24239519]

71. Tully PJ, Baker RA. Depression, anxiety, and cardiac morbidity outcomes after coronary artery bypass surgery: A contemporary and practical review. J Geriatr Cardiol 2012 Jun;9(2):197-208 [FREE Full text] [doi: 10.3724/SP.J.1263.2011.12221] [Medline: 22916068]

72. Taggart DP. Thomas B. Ferguson Lecture. Coronary artery bypass grafting is still the best treatment for multivessel and left main disease, but patients need to know. Ann Thorac Surg 2006 Dec;82(6):1966-1975. [doi: 10.1016/j.athoracsur.2006.06.035] [Medline: 17126093 ]

73. Connerney I, Shapiro PA, McLaughlin JS, Bagiella E, Sloan RP. Relation between depression after coronary artery bypass surgery and 12-month outcome: A prospective study. Lancet 2001 Nov 24;358(9295):1766-1771. [doi: 10.1016/S0140-6736(01)06803-9] [Medline: 11734233]

74. Tully PJ, Baker RA, Winefield HR, Turnbull DA. Depression, anxiety disorders and Type D personality as risk factors for delirium after cardiac surgery. Aust N Z J Psychiatry 2010 Nov;44(11):1005-1011. [doi: 10.3109/00048674.2010.495053] [Medline: 21034183]

75. Fráguas JR, Ramadan ZB, Pereira AN, Wajngarten M. Depression with irritability in patients undergoing coronary artery bypass graft surgery: The cardiologist's role. Gen Hosp Psychiatry 2000;22(5):365-374. [Medline: 11020543]

76. Rafanelli C, Roncuzzi R, Milaneschi Y. Minor depression as a cardiac risk factor after coronary artery bypass surgery. Psychosomatics 2006;47(4):289-295. [doi: 10.1176/appi.psy.47.4.289] [Medline: 16844886]

77. Gehi A, Haas D, Pipkin S, Whooley MA. Depression and medication adherence in outpatients with coronary heart disease: Findings from the Heart and Soul Study. Arch Intern Med 2005 Nov 28;165(21):2508-2513 [FREE Full text] [doi: 10.1001/archinte.165.21.2508] [Medline: 16314548 ]

78. Hohn N, Langer S, Kalder J, Jacobs MJ, Marx G, Eisert A. Optimizing the pharmacotherapy of vascular surgery patients by medication reconciliation. J Cardiovasc Surg (Torino) 2014 Apr;55(2 Suppl 1):175-181. [Medline: 24796911]

79. Cardiac Care Network of Ontario, Heart and Stroke Foundation, Ontario Stroke Network. Shaping the Future of Vascular Health: An Integrated Vascular Health Blueprint for Ontario. Toronto, ON: Ministry of Health and Long-Term Care; 2012 Aug. URL: http://www.ccn.on.ca/ccn public/uploadfiles/files/

Integrated\%20Vascular\%20Health\%20Blueprint\%20for\%20Ontario August\%202012.pdf [accessed 2016-05-02] [WebCite Cache ID 6hD59c2QX]

80. United Kingdom Department of Health. Cardiovascular Disease Outcomes Strategy: Improving Outcomes for People With or at Risk of Cardiovascular Disease. London, UK: Department of Health; 2013 Mar. URL: https://www.gov.uk/government/ uploads/system/uploads/attachment_data/file/217118/9387-2900853-CVD-Outcomes_web1.pdf [accessed 2016-05-02] [WebCite Cache ID 6hD5DJEEy]

81. Ontario Ministry of Health and Long-Term Care. Patients First: Action Plan for Health Care. Toronto, ON: Ministry of Health and Long-Term Care; 2015 Feb. URL: http://www.health.gov.on.ca/en/ms/ecfa/healthy_change/docs/rep_patientsfirst. pdf [accessed 2016-05-02] [WebCite Cache ID 6hD5Gs6pi]

82. Philips Critical Care. Rapid response with Early Warning Scoring URL: http://www.usa.philips.com/healthcare/articles/ early-warning-scoring-tools-for-rapid-response [accessed 2016-05-02] [WebCite Cache ID 6hD5KYqOG]

83. Philips Enterprise Telehealth. eTrAC program: Telehealth program for the transition to ambulatory care URL: http://www. usa.philips.com/healthcare/solutions/enterprise-telehealth/home-telehealth/readmission-manager/etrac [accessed 2016-05-02] [WebCite Cache ID 6hD5091vn]

84. QoC Health. Overview URL: http://qochealth.com/what-we-do/ [accessed 2016-05-02] [WebCite Cache ID 6hD5RBOrA]

85. Bellomo R, Ackerman M, Bailey M, Beale R, Clancy G, Danesh V, Vital Signs to Identify, Target, and Assess Level of Care Study (VITAL Care Study) Investigators. A controlled trial of electronic automated advisory vital signs monitoring in general hospital wards. Crit Care Med 2012 Aug;40(8):2349-2361. [doi: 10.1097/CCM.0b013e318255d9a0] [Medline: 22809908]

86. Furze G, Cox H, Morton V, Chuang LH, Lewin RJ, Nelson P, et al. Randomized controlled trial of a lay-facilitated angina management programme. J Adv Nurs 2012 Oct;68(10):2267-2279. [Medline: 2222948] 
87. Wayne N, Perez DF, Kaplan DM, Ritvo P. Health coaching reduces HbA1c in type 2 diabetic patients from a lower-socioeconomic status community: A randomized controlled trial. J Med Internet Res 2015;17(10):e224 [FREE Full text] [doi: 10.2196/jmir.4871] [Medline: 26441467]

88. McGillion MH, Watt-Watson J, Stevens B, Lefort SM, Coyte P, Graham A. Randomized controlled trial of a psychoeducation program for the self-management of chronic cardiac pain. J Pain Symptom Manage 2008 Aug;36(2):126-140. [doi: 10.1016/j.jpainsymman.2007.09.015] [Medline: 18395397]

89. Martin F, Turner A, Wallace L, Bradbury N. Conceptualising self-management interventions for people with early stage dementia. Eur J Aging 2013. [doi: 10.1007/s10433-012-0253-5.23]

90. Turner A, Batehup L, Surendranath S. Improving the wellbeing of cancer patients in the community. Nurs Pract 2011 Mar;59:75-76.

91. LeFort SM, Gray-Donald K, Rowat KM, Jeans ME. Randomized controlled trial of a community-based psychoeducation program for the self-management of chronic pain. Pain 1998 Feb;74(2-3):297-306. [Medline: 9520244]

92. Leeuw M, Goossens ME, Linton SJ, Crombez G, Boersma K, Vlaeyen JW. The fear-avoidance model of musculoskeletal pain: Current state of scientific evidence. J Behav Med 2007 Feb;30(1):77-94. [doi: 10.1007/s10865-006-9085-0] [Medline: $\underline{17180640]}$

93. Karwoski L, Garratt GM, Ilardi SS. On the integration of cognitive-behavioral therapy for depression and positive psychology. J Cogn Psychother 2006 Jun 01;20(2):159-170. [doi: 10.1891/088983906780639763]

94. Hergenrather KC, Geishecker S, Clark G, Rhodes SD. A pilot test of the HOPE Intervention to explore employment and mental health among African American gay men living with HIV/AIDS: Results from a CBPR study. AIDS Educ Prev 2013 Oct;25(5):405-422. [doi: 10.1521/aeap.2013.25.5.405] [Medline: 24059878]

95. Whiteman B, Grant-Pearce C, Cooper L, Turner A. Surviving cancer: Pilot of a Web-based self-management support programme, eHOPE. Lancet 2015 Nov;386:S7. [doi: 10.1016/S0140-6736(15)00845-4]

96. Semple JL, Sharpe S, Murnaghan ML, Theodoropoulos J, Metcalfe KA. Using a mobile app for monitoring post-operative quality of recovery of patients at home: A feasibility study. JMIR Mhealth Uhealth 2015 Feb 12;3(1):e18. [Medline: 25679]

97. Higgins J, Murnaghan L, Semple J, Sharpe S, Carvalhana I, Theodoropoulos J. Examining the feasibility of a mobile Web-based follow-up system for post-operative ACL reconstruction patients. Arthroscopy 2013 Oct;29(10):e176-e177. [doi: 10.1016/j.arthro.2013.07.245]

98. Hinchley A. Understanding Version 3 Guide: A Primer on the HL7 Version 3 Communication Standard. Munich, Germany: Alexander Moench Publishing; 2007.

99. Shapiro SS. The state and evolution of privacy by design. In: Proceedings of the 2012 ACM Conference on Computer and Communications Security. New York, NY: ACM; 2012 Presented at: 2012 ACM Conference on Computer and Communications Security; October 16-18, 2012; Raleigh, NC p. 1053. [doi: 10.1145/2382196.2382324]

100. Rogers ML, Patterson E, Chapman R, Render M. Usability testing the relation of clinical information systems to patient safety. In: Henriksen K, Battles JB, Marks ES, Lewin DI, editors. Advances in Patient Safety: From Research to Implementation. Volume 2: Concepts and Methodology. Rockville, MD: Agency for Healthcare Research and Quality; 2005:365-378.

101. McGillion M, Carroll SL, Metcalfe K, Arthur HM, Victor JC, McKelvie R, et al. Development of a patient decision aid for people with refractory angina: Protocol for a three-phase pilot study. Health Qual Life Outcomes 2014 Jun 11;12:93. [Medline: 2492051]

102. Johnsen HM, Sletteb $\varnothing$, Fossum M. Registered nurses' clinical reasoning in home healthcare clinical practice: A think-aloud study with protocol analysis. Nurse Educ Today 2016 May;40:95-100. [doi: 10.1016/j.nedt.2016.02.023] [Medline: 27125156]

103. Lax LR, Russell ML, Nelles LJ, Smith CM. Scaffolding knowledge building in a Web-based communication and cultural competence program for international medical graduates. Acad Med 2009 Oct;84(10 Suppl):S5-S8. [doi: 10.1097/ACM.0b013e3181b37b4d] [Medline: 19907385]

104. Kuniavsky M. Observing the User Experience: A Practitioner's Guide to User Research. San Francisco, CA: Morgan Kaufmann Publishers; 2003.

105. Schensul S, LeCompte MD, Schensul SL. Essential Ethnographic Methods: Observations, Interviews, and Questionnaires. Lanham, MD: Altamira Press; 1999.

106. Cleeland CS. The Brief Pain Inventory: User Guide. Houston, TX: University of Texas MD Anderson Cancer Centre; 2009.

107. Watt-Watson J, Chung F, Chan VW, McGillion M. Pain management following discharge after ambulatory same-day surgery. J Nurs Manag 2004 May;12(3):153-161. [doi: 10.1111/j.1365-2834.2004.00470.x] [Medline: 15089952]

108. Ware JJ, Kosinski M, Keller SD. A 12-item short-form health survey: Construction of scales and preliminary tests of reliability and validity. Med Care 1996 Mar;34(3):220-233. [Medline: 8628042]

109. Ware JEJ, Sherbourne CD. The MOS 36-item short-form health survey (SF-36). I. Conceptual framework and item selection. Med Care 1992 Jun;30(6):473-483. [Medline: 1593914]

110. Dennis M, Kadri A, Coffey J. Depression in older people in the general hospital: A systematic review of screening instruments. Age Ageing 2012 Mar;41(2):148-154 [FREE Full text] [doi: 10.1093/ageing/afr169] [Medline: 22236655] 
111. Rinaldi P, Mecocci P, Benedetti C, Ercolani S, Bregnocchi M, Menculini G, et al. Validation of the five-item geriatric depression scale in elderly subjects in three different settings. J Am Geriatr Soc 2003 May;51(5):694-698. [Medline: 12752847]

112. Macrae W, Davies H. Chronic postsurgical pain. In: Crombie IK, Croft PR, Linton SJ, LeResche L, Von Korff M, editors. Epidemiology of Pain. Seattle, WA: IASP Press; 1999:125-142.

113. Guerriere DN, Ungar WJ, Corey M, Croxford R, Tranmer JE, Tullis E, et al. Evaluation of the ambulatory and home care record: Agreement between self-reports and administrative data. Int J Technol Assess Health Care 2006;22(2):203-210. [doi: 10.1017/S0266462306051026] [Medline: 16571196$]$

114. Guerriere DN, Coyte PC. The ambulatory and home care record: A methodological framework for economic analyses in end-of-life care. J Aging Res 2011;2011:374237 [FREE Full text] [doi: 10.4061/2011/374237] [Medline: 21629752]

115. Guerriere DN, Tranmer JE, Ungar WJ, Manoharan V, Coyte PC. Valuing care recipient and family caregiver time: A comparison of methods. Int J Technol Assess Health Care 2008;24(1):52-59. [doi: 10.1017/S0266462307080075] [Medline: 18218169]

116. Guerriere DN, Choinière M, Dion D, Peng P, Stafford-Coyte E, Zagorski B, et al. The Canadian STOP-PAIN project - Part 2: What is the cost of pain for patients on waitlists of multidisciplinary pain treatment facilities? Can J Anaesth 2010 Jun;57(6):549-558. [doi: 10.1007/s12630-010-9306-4] [Medline: 20414821]

117. McGillion MH, Croxford R, Watt-Watson J, Lefort S, Stevens B, Coyte P. Cost of illness for chronic stable angina patients enrolled in a self-management education trial. Can J Cardiol 2008 Oct;24(10):759-764 [FREE Full text] [Medline: 18841254]

118. Robinson ME, Riley JL3, Myers CD, Papas RK, Wise EA, Waxenberg LB, et al. Gender role expectations of pain: Relationship to sex differences in pain. J Pain 2001 Oct;2(5):251-257. [doi: 10.1054/jpai.2001.24551] [Medline: 14622803]

119. Robinson ME, Wise EA, Gagnon C, Fillingim RB, Price DD. Influences of gender role and anxiety on sex differences in temporal summation of pain. J Pain 2004 Mar;5(2):77-82. [doi: 10.1016/j.jpain.2003.11.004] [Medline: 15042515]

120. Defrin R, Eli I, Pud D. Interactions among sex, ethnicity, religion, and gender role expectations of pain. Gend Med 2011 Jun;8(3):172-183. [doi: 10.1016/j.genm.2011.04.001] [Medline: 21602107]

121. Alabas OA, Tashani OA, Tabasam G, Johnson MI. Gender role affects experimental pain responses: A systematic review with meta-analysis. Eur J Pain 2012 Oct;16(9):1211-1223. [doi: 10.1002/j.1532-2149.2012.00121.x] [Medline: 22434689]

122. Defrin R, Shramm L, Eli I. Gender role expectations of pain is associated with pain tolerance limit but not with pain threshold. Pain 2009 Sep;145(1-2):230-236. [doi: 10.1016/j.pain.2009.06.028] [Medline: 19615821]

123. Racine M, Tousignant-Laflamme Y, Kloda LA, Dion D, Dupuis G, Choinière M. A systematic literature review of 10 years of research on sex/gender and pain perception - part 2: Do biopsychosocial factors alter pain sensitivity differently in women and men? Pain 2012 Mar;153(3):619-635. [doi: 10.1016/j.pain.2011.11.026] [Medline: 22236999]

124. Zan S, Agboola S, Moore SA, Parks KA, Kvedar JC, Jethwani K. Patient engagement with a mobile Web-based telemonitoring system for heart failure self-management: A pilot study. JMIR Mhealth Uhealth 2015;3(2):e33 [FREE Full text] [doi: 10.2196/mhealth.3789] [Medline: 25842282]

125. Pope C, Ziebland S, Mays N. Qualitative research in health care. Analysing qualitative data. BMJ 2000 Jan 8;320(7227):114-116 [FREE Full text] [Medline: $\underline{\text { 10625273] }}$

126. Hulley S. Designing Clinical Research: An Epidemiologic Approach. 4th edition. Philadelphia, PA: Wolters Kluwer Health; 2013.

127. Kish L. Survey Sampling. New York, NY: John Wiley \& Sons; 1965.

128. Moher D, Schulz KF, Altman D, CONSORT Group (Consolidated Standards of Reporting Trials). The CONSORT statement: Revised recommendations for improving the quality of reports of parallel-group randomized trials. JAMA 2001 Apr 18;285(15):1987-1991. [Medline: 11308435]

129. Brown H, Prescott R. Applied Mixed Models in Medicine. 2nd edition. New York, NY: John Wiley \& Sons; 2006.

130. Liang K, Zeger S. Longitudinal data analysis using generalized linear models. Biometrika 1986;73:13-22. [Medline: 2942271]

131. Laird NM, Ware JH. Random-effects models for longitudinal data. Biometrics 1982 Dec;38(4):963-974. [Medline: 7168798]

132. Davidian M, Giltinan DM. Nonlinear Models for Repeated Measurement Data. New York, NY: Chapman \& Hall; 1995.

133. Lillie EO, Patay B, Diamant J, Issell B, Topol EJ, Schork NJ. The n-of-1 clinical trial: The ultimate strategy for individualizing medicine? Per Med 2011 Mar;8(2):161-173 [FREE Full text] [doi: 10.2217/pme.11.7] [Medline: 21695041]

134. Barr C, Marois M, Sim I, Schmid CH, Wilsey B, Ward D, et al. The PREEMPT study - Evaluating smartphone-assisted n-of-1 trials in patients with chronic pain: Study protocol for a randomized controlled trial. Trials 2015;16:67 [FREE Full text] [doi: 10.1186/s13063-015-0590-8] [Medline: 25881274]

135. Briggs A, Nixon R, Dixon S, Thompson S. Parametric modelling of cost data: Some simulation evidence. Health Econ 2005 Apr;14(4):421-428. [doi: 10.1002/hec.941] [Medline: 15685641]

136. Barber J, Thompson S. Multiple regression of cost data: Use of generalised linear models. J Health Serv Res Policy 2004 Oct;9(4):197-204. [doi: 10.1258/1355819042250249] [Medline: 15509405]

137. Gold M, Siegel J, Russell L, Weinstein M. Cost-Effectiveness in Health and Medicine. New York, NY: Oxford University Press; 1996. 
138. Drummond M, Sculpher M, Torrance G, O'Brien B, Stoddart G. Methods for the Economic Evaluation of Health Care Programmes. 3rd edition. New York, NY: Oxford University Press; 2005.

139. Hoch JS, Rockx MA, Krahn AD. Using the net benefit regression framework to construct cost-effectiveness acceptability curves: An example using data from a trial of external loop recorders versus Holter monitoring for ambulatory monitoring of “community acquired” syncope. BMC Health Serv Res 2006;6:68 [FREE Full text] [doi: 10.1186/1472-6963-6-68] [Medline: 16756680]

140. Jimison H, Gorman P, Woods S, Nygren P, Walker M, Norris S, et al. Barriers and Drivers of Health Information Technology Use for the Elderly, Chronically Ill, and Underserved. Rockville, MD: Agency for Healthcare Research and Quality; 2008 Nov. URL: http://www.ahrq.gov/research/findings/evidence-based-reports/hitbartp.html [accessed 2016-05-10] [WebCite Cache ID 6hPMzrDVL]

141. Creswell JW. Research Design: Qualitative, Quantitative, and Mixed Methods Approaches. 4th edition. Thousand Oaks, CA: Sage Publications; 2013.

142. Peter E, Spalding K, Kenny N, Conrad P, McKeever P, Macfarlane A. Neither seen nor heard: Children and homecare policy in Canada. Soc Sci Med 2007 Apr;64(8):1624-1635. [doi: 10.1016/j.socscimed.2006.12.002] [Medline: 17240503]

143. Peter E. Home health care: Ethics, politics and policy. In: Storch JL, Starzomski R, Rodney P, editors. Toward a Moral Horizon: Nursing Ethics for Leadership and Practice. 2nd edition. Toronto, ON: Pearson Education Canada; 2013:384-397.

144. Emerson RM. Working with 'key incidents'. In: Seale C, Gobo G, Gubrium JF, Silverman D, editors. Qualitative Research Practice. Thousand Oaks, CA: Sage Publications; 2007:427-442.

145. Kincheloe J, McLaren P. Rethinking critical theory qualitative research. In: Denzin NK, Lincoln YS, editors. The SAGE Handbook of Qualitative Research. 3rd edition. Thousand Oaks, CA: Sage Publications; 2005:303-341.

146. Angen MJ. Evaluating interpretive inquiry: Reviewing the validity debate and opening the dialogue. Qual Health Res 2000 May;10(3):378-395. [Medline: 10947483]

\section{Abbreviations}

AHCR: Ambulatory Home Care Record

BPI-SF: Brief Pain Inventory-Short Form

CAM: Confusion Assessment Method

CARD: Cardiac

CaVS: cardiac and vascular surgery

CIHI: Canadian Institute for Health Information

CIHR: Canadian Institutes of Health Research

CPSP: chronic postsurgical pain

eCC: eCare Coordinator

ECG: electrocardiogram

eTrAC: Transition to Ambulatory Care

EWS: early warning score

GDS-5: five-question version of the Geriatric Depression Scale

GREP: Gender Role Expectations of Pain

HOPE: Help to Overcome Problems Effectively

HR: hazard ratio

HRQL: health-related quality of life

ICU: intensive care unit

iHOPE: Internet-based Help to Overcome Problems Effectively

IWRS: Interactive Web Randomization System

MoHLTC: Ministry of Health and Long-Term Care

N/A: not applicable

PCI: percutaneous coronary intervention

POISE: PeriOperative ISchemic Evaluation

postop: postoperative

PRAS: pain relief after surgery

PROMIS: Patient-Reported Outcomes Measurement Information System

QALY: quality-adjusted life year

RA: research assistant

RCT: randomized controlled trial

SF-12v2: Short-Form 12 version 2

SpO2: peripheral oxygen saturation

SSI: surgical site infection

SVN: SMArTVIEW Nurse 
THE SMArTVIEW, CoVeRed: TecHnology-Enabled remote monitoring and Self-MAnagemenT—VIsion for patient EmpoWerment following Cardiac and VasculaR surgery

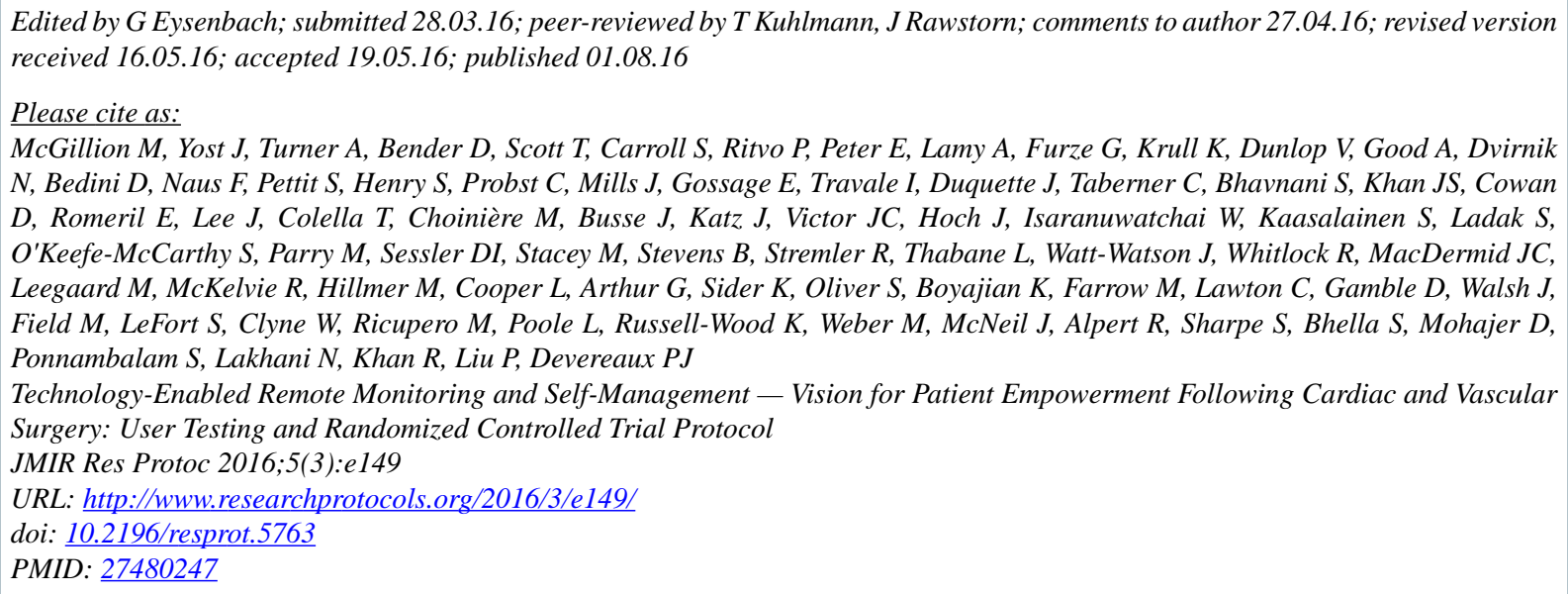

CMichael McGillion, Jennifer Yost, Andrew Turner, Duane Bender, Ted Scott, Sandra Carroll, Paul Ritvo, Elizabeth Peter, Andre Lamy, Gill Furze, Kirsten Krull, Valerie Dunlop, Amber Good, Nazari Dvirnik, Debbie Bedini, Frank Naus, Shirley Pettit, Shaunattonie Henry, Christine Probst, Joseph Mills, Elaine Gossage, Irene Travale, Janine Duquette, Christy Taberner, Sanjeev Bhavnani, James S Khan, David Cowan, Eric Romeril, John Lee, Tracey Colella, Manon Choinière, Jason Busse, Joel Katz, J Charles Victor, Jeffrey Hoch, Wanrudee Isaranuwatchai, Sharon Kaasalainen, Salima Ladak, Sheila O'Keefe-McCarthy, Monica Parry, Daniel I Sessler, Michael Stacey, Bonnie Stevens, Robyn Stremler, Lehana Thabane, Judy Watt-Watson, Richard Whitlock, Joy C MacDermid, Marit Leegaard, Robert McKelvie, Michael Hillmer, Lynn Cooper, Gavin Arthur, Krista Sider, Susan Oliver, Karen Boyajian, Mark Farrow, Chris Lawton, Darryl Gamble, Jake Walsh, Mark Field, Sandra LeFort, Wendy Clyne, Maria Ricupero, Laurie Poole, Karsten Russell-Wood, Michael Weber, Jolene McNeil, Robyn Alpert, Sarah Sharpe, Sue Bhella, David Mohajer, Sem Ponnambalam, Naeem Lakhani, Rabia Khan, Peter Liu, PJ Devereaux. Originally published in JMIR Research Protocols (http://www.researchprotocols.org), 01.08.2016. This is an open-access article distributed under the terms of the Creative Commons Attribution License (http://creativecommons.org/licenses/by/2.0/), which permits unrestricted use, distribution, and reproduction in any medium, provided the original work, first published in JMIR Research Protocols, is properly cited. The complete bibliographic information, a link to the original publication on http://www.researchprotocols.org, as well as this copyright and license information must be included. 